\title{
Space Shuttle Main Engine - The Relentless Pursuit of Improvement
}

\author{
Katherine P. Van Hooser.* \\ NASA Marshall Space Flight Center, Huntsville, Alabama 35812 \\ Douglas P. Bradley. ${ }^{\dagger}$ \\ Pratt \& Whitney Rocketdyne, Canoga Park, California 91303
}

\begin{abstract}
The Space Shuttle Main Engine (SSME) is the only reusable large liquid rocket engine ever developed. The specific impulse delivered by the staged combustion cycle, substantially higher than previous rocket engines, minimized volume and weight for the integrated vehicle. The dual pre-burner configuration permitted precise mixture ratio and thrust control while the fully redundant controller and avionics provided a very high degree of system reliability and health diagnosis. The main engine controller design was the first rocket engine application to incorporate digital processing. The engine was required to operate at a high chamber pressure to minimize engine volume and weight. Power level throttling was required to minimize structural loads on the vehicle early in flight and acceleration levels on the crew late in ascent. Fatigue capability, strength, ease of assembly and disassembly, inspectability, and materials compatibility were all major considerations in achieving a fully reusable design. During the multi-decade program the design evolved substantially using a series of block upgrades. A number of materials and manufacturing challenges were encountered throughout SSME's history. Significant development was required for the final configuration of the high pressure turbopumps. Fracture control was implemented to assess life limits of critical materials and components. Survival in the hydrogen environment required assessment of hydrogen embrittlement. Instrumentation systems were a challenge due to the harsh thermal and dynamic environments within the engine. Extensive inspection procedures were developed to assess the engine components between flights. The Space Shuttle Main Engine achieved a remarkable flight performance record. All flights were successful with only one mission requiring an ascent abort condition, which still resulted in an acceptable orbit and mission. This was achieved in large part via extensive ground testing to fully characterize performance and to establish acceptable life limits. During the program over a million seconds of accumulated test and flight time was achieved. Post flight inspection and assessment was a key part of assuring proper performance of the flight hardware. By the end of the program the predicted reliability had improved by a factor of four. These unique challenges, evolution of the design, and the resulting reliability will be discussed in this paper.
\end{abstract}

\section{The Amazing Space Shuttle Main Engine}

The Space Shuttle Main Engine (SSME) was the only large reusable, liquid rocket engine in the world. It operated at greater temperature extremes than any mechanical system in common use today. The SSME used as fuel the second coldest liquid on Earth, liquid hydrogen at -423 degrees Fahrenheit. When the hydrogen burned with liquid oxygen, the temperature in the engine's main combustion chamber reached +6000 degrees Fahrenheit, higher than the boiling point of iron. The maximum equivalent horsepower developed by the three SSMEs used on every Space Shuttle flight was just over 37 million horsepower, equivalent to the output of 13 Hoover Dams. Although not much larger than an automobile engine, the SSME high-pressure fuel turbopump generates 70,000 horsepower or 70 horsepower for each pound of its weight, while an automobile engine generated approximately one-half horsepower for each pound of its weight. Even though the SSME weighed one-seventh as much as a locomotive

\footnotetext{
* NASA SSME Chief Engineer, NASA/MSFC/EE02

${ }^{\dagger}$ Pratt \& Whitney Rocketdyne SSME Chief Engineer, RAA50
} 
engine, its high-pressure fuel turbopump alone delivered as much horsepower as 28 locomotives, while its highpressure oxidizer turbopump delivered the equivalent horsepower for 11 more. SSME was the first engine with both chamber pressure and mixture ratio close-loop control, with autonomous controller and health management, and with variable throttling. SSMEs were the only large rocket engines in the world to achieve one million seconds of operation consuming approximately 300 million gallons of propellant, and they operated safely and successfully on all 135 Space Shuttle flights.

The SSME was a staged-combustion cycle engine with a nominal burn time in flight of approximately 8.5 minutes at $104.5 \%$ of rated power level (RPL). A simplified SSME propellant flow schematic is shown in Figure 1.

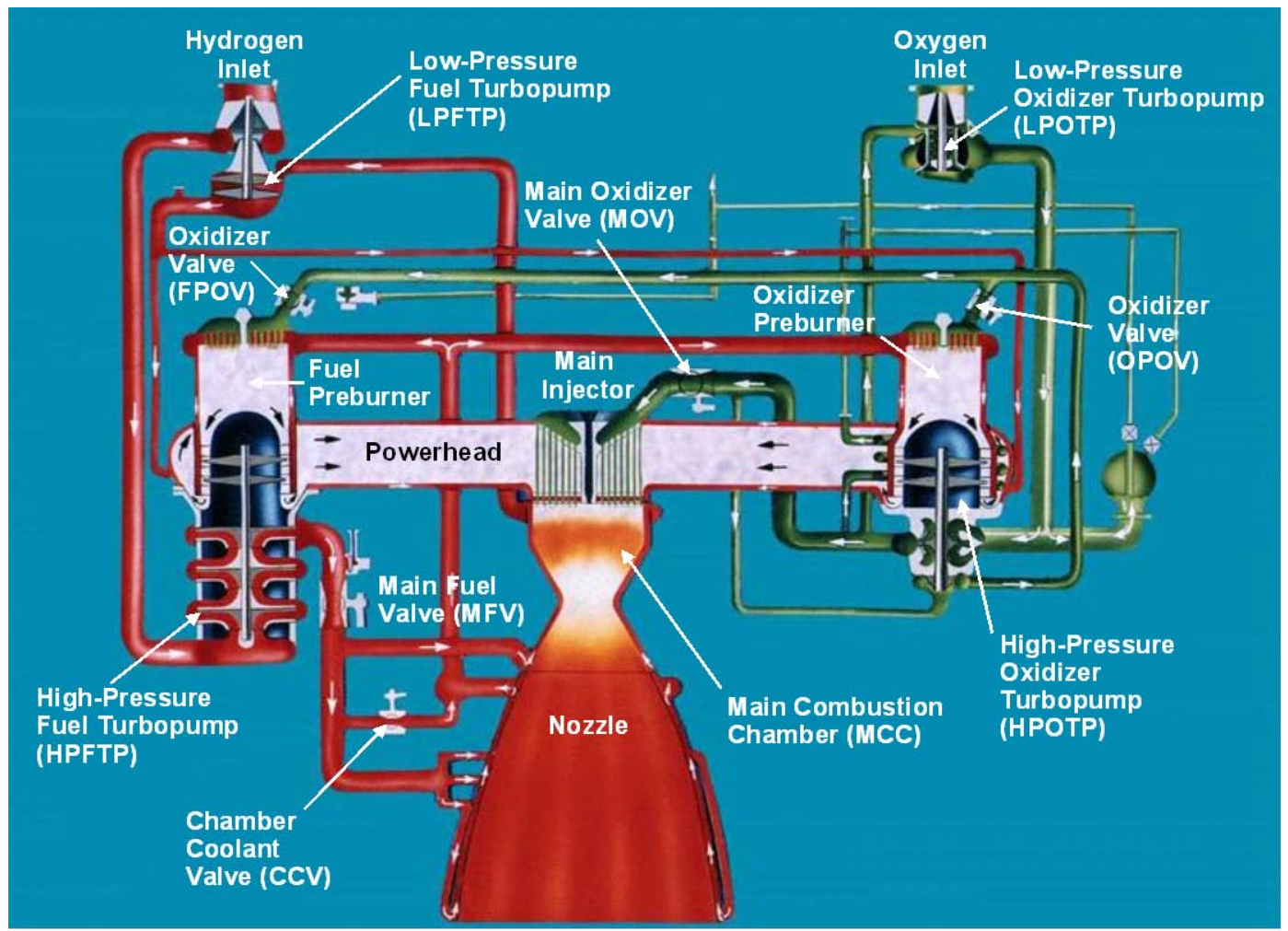

Figure 1. Simplified SSME Propellant Flow Schematic

As seen in Figure 1, liquid hydrogen entered the engine at the inlet to the Low Pressure Fuel Turbopump (LPFTP). The LPFTP boosted the pressure of the fuel sufficiently to prevent cavitation of the High Pressure Fuel Turbopump (HPFTP). The fuel flowed from the HPFTP pump discharge and split three ways. Part of the fuel was used to cool the Main Combustion Chamber (MCC). This MCC coolant flow was then directed to the LPFTP, where the then gaseous hydrogen powered the LPFTP turbine. After discharging from the turbine, the flow then entered a coolant jacket around the engine powerhead. This then hot gaseous hydrogen eventually entered the main injector for final engine combustion. The remainder of the pump discharge flow, after cooling the nozzle, mixed with bypass flow and was directed to the preburners. The two preburners operated at a fuel-rich mixture ratio, generating hot, hydrogen-rich steam to power the two high-pressure turbopump turbines. Following discharge from the turbines, the hot gas was directed by the powerhead to the main injector for final combustion. ${ }^{2}$

Liquid oxygen entered the engine at the inlet to the Low Pressure Oxidizer Turbopump (LPOTP) as seen in Figure 1. The LPOTP boosted the pressure of the oxidizer sufficiently to prevent cavitation of the High Pressure Oxidizer Turbopump (HPOTP). The HPOTP increased the oxidizer pressure, and the majority of the flow went directly to the main injector for engine combustion. A portion of the HPOTP pump discharge flow was tapped off to enter a boost pump at the end of the HPOTP and was used to provide oxidizer at even higher pressure to the preburners. Another portion of the HPOTP pump discharge flow was tapped off to power the LPOTP hydraulic turbine. The LPOTP turbine flow then merged with the main LPOTP discharge flow. ${ }^{2}$

The staged-combustion cycle yields both high efficiency and system complexity along with high turbopump speeds and chamber pressures. The engine's low-weight compact design and high efficiency lead to a world-class 
thrust-to-weight ratio of 66 at full power level. SSME performance parameters for the final engine configuration are shown in Figure 2. Throttle requirements ranged from 67\% RPL, during the time early in ascent when maximum dynamic pressure was reached on the vehicle and again near Main Engine Cut-Off when the thrust was reduced to maintain no more than a 3G acceleration, to 104.5\% RPL at mainstage and 109\% RPL for certain abort modes (which were never implemented in flight). Figure 3 depicts a nominal mission profile. The control system employed redundancy known as fail-op, fail safe which required the engines to operate normally for the first control failure and then to shut down safely for the second failure.

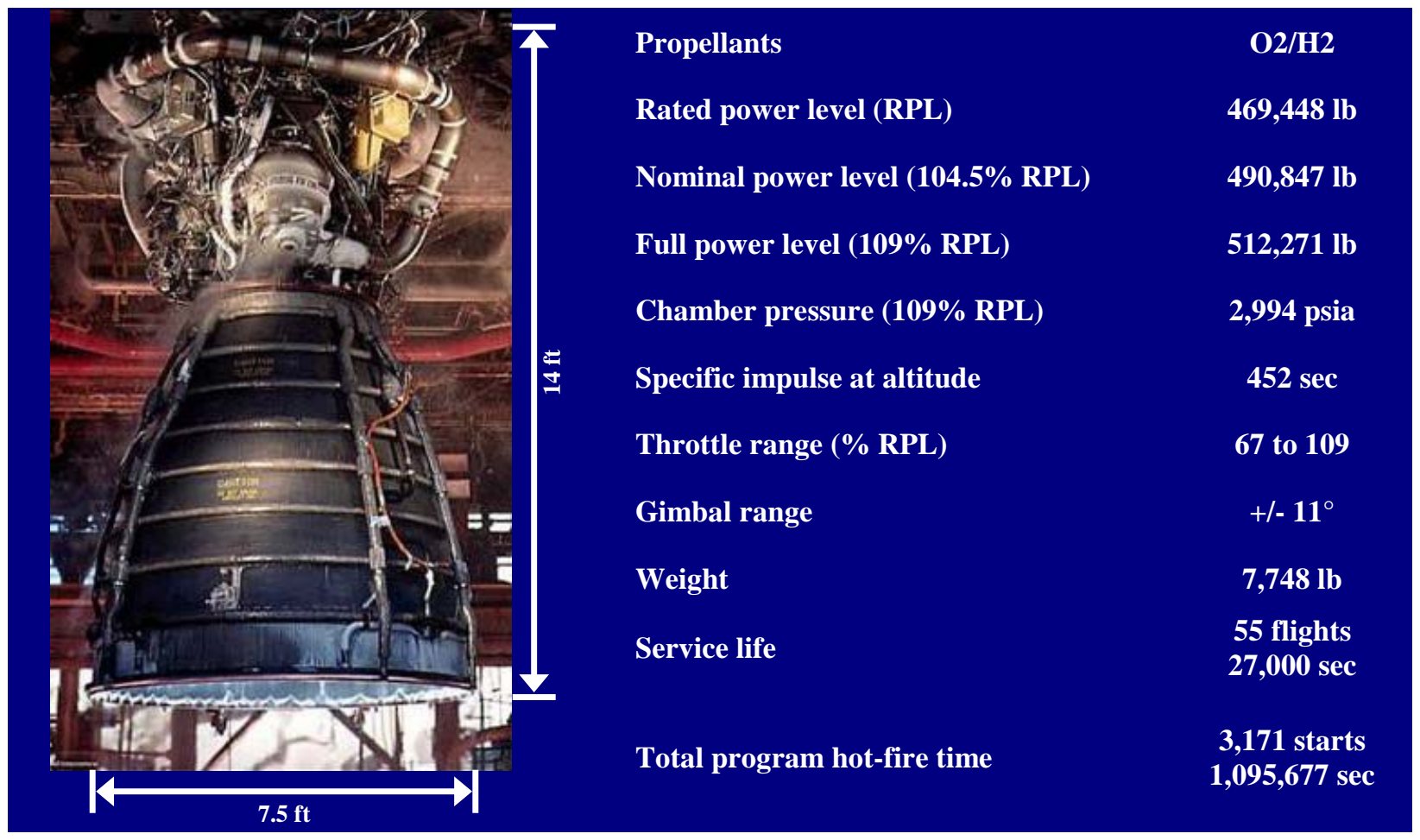

Figure 2. SSME Operational Characteristics

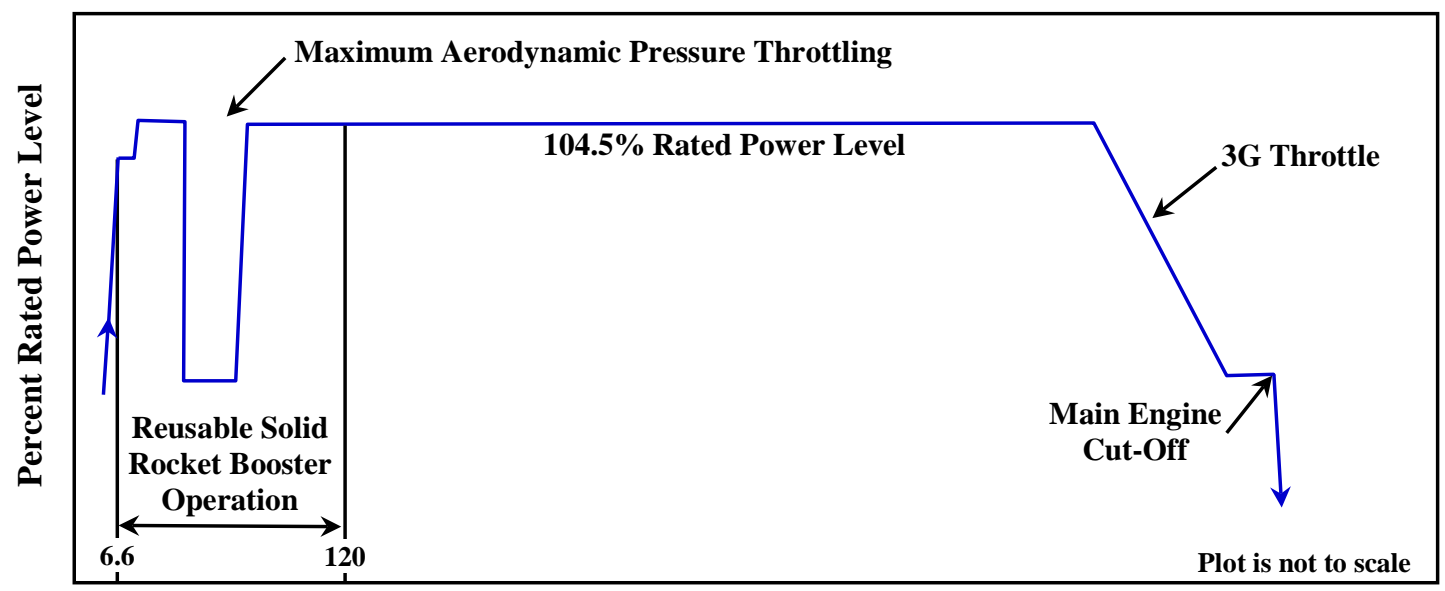

Time in seconds

Figure 3. Typical SSME Mission Profile 


\section{Design Evolution ${ }^{1,2,5}$}

The Space Shuttle Main Engine (SSME) was designed and developed by Pratt \& Whitney Rocketdyne under contract to the NASA Marshall Space Flight Center. The contract was awarded in 1971, and work on the engine began in 1972. SSME engine-level testing commenced in 1975, and in the six years of development between the start of testing and the first flight, numerous SSME hardware redesigns took place. These design-test-fail-fix iterations are typical of any engine development program, especially within the context of development of a new staged-combustion cycle, high thrust-to-weight, reusable liquid hydrogen engine. Solutions to the problems depended on the severity of the issue. Redesigns were implemented as soon as possible for many of the problems that were discovered, some issues could wait for resolution, and other problems were judged to be acceptable and were managed with life or inspection limits.

In the SSME 40-year history, all of the major components were modified and improved. Incremental, small changes were certified based on analysis and/or limited hot-fire testing. More extensive changes were introduced in "phase" and "block" changes in order to conduct flight certification test programs on several changes at the same time, thus reducing test costs. The design features in each upgraded configuration are listed in Table 1 and will be described below. Figure 4 provides a timeline showing when the major block improvements were incorporated.

Table 1. SSME Configuration Details

\begin{tabular}{|c|c|c|c|c|c|c|}
\hline $\begin{array}{c}\text { First } \\
\text { Manned } \\
\text { Orbital } \\
\text { Flight } \\
\end{array}$ & $\begin{array}{c}\text { Full Power Level } \\
\text { or } \\
\text { Phase I }\end{array}$ & Phase II & Block I & Block IA & Block IIA & Block II \\
\hline $\begin{array}{l}1^{\text {st }} \text { Flight: } \\
\text { STS-1 } \\
\text { 4/12/1981 }\end{array}$ & $\begin{array}{l}1^{\text {st }} \text { Flight: } \\
\text { STS-6 } \\
\text { 4/4/1983 }\end{array}$ & $\begin{array}{l}1^{\text {st }} \text { Flight: } \\
\text { STS-26R } \\
\text { 9/29/1988 }\end{array}$ & $\begin{array}{l}1^{\text {st }} \text { Flight: } \\
\text { STS-70 } \\
\text { 7/13/1995 }\end{array}$ & $\begin{array}{c}1^{\text {st }} \text { Flight: } \\
\text { STS-73 } \\
\text { 10/20/1995 }\end{array}$ & $\begin{array}{l}1^{\text {st }} \text { Flight: } \\
\text { STS-89 } \\
1 / 22 / 1998\end{array}$ & $\begin{array}{l}1^{\text {st }} \text { Flight: } \\
\text { STS-104 } \\
7 / 12 / 2001\end{array}$ \\
\hline $\begin{array}{l}\text {-Baseline } \\
\text { Engine }\end{array}$ & $\begin{array}{l}\text {-Powerhead/Ducts } \\
\text { - HGM fuel bowl liner } \\
\text { mods } \\
\text { - Lox post support } \\
\text { pins in FPB } \\
\text { - New flow meter } \\
\text { straightener } \\
\text { - LOX post shields } \\
\text {-HPFTP } \\
\text { - Kel-F seals } \\
\text { - Replaces stepped } \\
\text { interstage seals with } \\
\text { smooth } \\
\text { - Increased clearance } \\
\text { turbine blade } \\
\text { clearance to tip seal } \\
\text {-HPOTP } \\
\text { - Housing material } \\
\text { changed (INCO 903) } \\
\text {-LPFTP } \\
\text { - Revised blocking } \\
\text { area } \\
\text {-LPOTP } \\
\text { - Turbine discharge } \\
\text { turning vane mod } \\
\text {-Avionics } \\
\text { •Nozzle } \\
\text { - Increased tube wall } \\
\text { thickness } \\
\text { - Added steam loop }\end{array}$ & $\begin{array}{l}\text { •HPFTP } \\
\text { - Shot-peened fir trees } \\
\text { - Large coolant discharge orifices } \\
\text { •HPOTP } \\
\text { - Bearing changes } \\
\text { - PBP damping seals } \\
\text { - Two-piece dampers } \\
\text { - Non-scalloped interstage seal } \\
\text { ring } \\
\text { - Tapered interstage seal } \\
\text { - Thick PBP bearing isolator } \\
\text { added thermal shield } \\
\text { - Bearing diametral clearances } \\
\text {-MCC } \\
\text { - EDNi reinforced outlet neck } \\
\text { - Burst diaphragm drainline } \\
\text { •HPF Duct Helium Barrier } \\
\text {-Avionics/Valves } \\
\text { - Increased strength MFV } \\
\text { housing } \\
\text { - Anti-backlash couplings } \\
\text { - Potted wireways } \\
\text { - Tight stack GCV } \\
\text { - Modified pressure sensor cavity } \\
\text { - Improved hot-gas temperature } \\
\text { sensor } \\
\text { - Spark igniter case structural } \\
\text { improvements } \\
\text { - 4k Hz monitor } \\
\text { - Skin temp sensor added to Anti- } \\
\text { flood Valve }\end{array}$ & $\begin{array}{l}\text {-Phase Il+ } \\
\text { Powerhead } \\
\text { (Two Duct) } \\
\text { •Single Tube } \\
\text { HEX } \\
\text { •HPOTPIAT } \\
\\
\text { First Flight } \\
\text { STS-75: } \\
\text {-Thermocouples }\end{array}$ & \begin{tabular}{|l} 
Main Injector \\
Modifications \\
- Programmed \\
secondary \\
faceplate \\
coolant holes
\end{tabular} & $\begin{array}{l}\text {-Large Throat } \\
\text { MCC } \\
\text { - Cast } \\
\text { Inlet/Outlet } \\
\text { Elbows } \\
-20 \text {-hole fuel } \\
\text { sleeves } \\
\text {-Block II LPOTP } \\
\text {-Block II LPFTP } \\
\text {-A-Cal software } \\
\text { •Actuator spool } \\
\text { material } \\
\text { improvement } \\
\text { •Filtered check } \\
\text { valves } \\
\text { •Pressure sensor } \\
\text { improvements } \\
\text { First Flight } \\
\text { STS-96: } \\
\text { •Opened } \\
\text { boundary layer } \\
\text { coolant (BLC) } \\
\text { holes to minimize } \\
\text { for faceplate } \\
\text { erosion }\end{array}$ & \begin{tabular}{|l} 
•HPFTPIAT \\
•Main Fuel \\
Valve \\
•Non-integral \\
Spark Igniter \\
\\
First Flight \\
STS-117: \\
•Advanced \\
Health \\
Management \\
System \\
- Real-time \\
vibration \\
monitoring
\end{tabular} \\
\hline
\end{tabular}




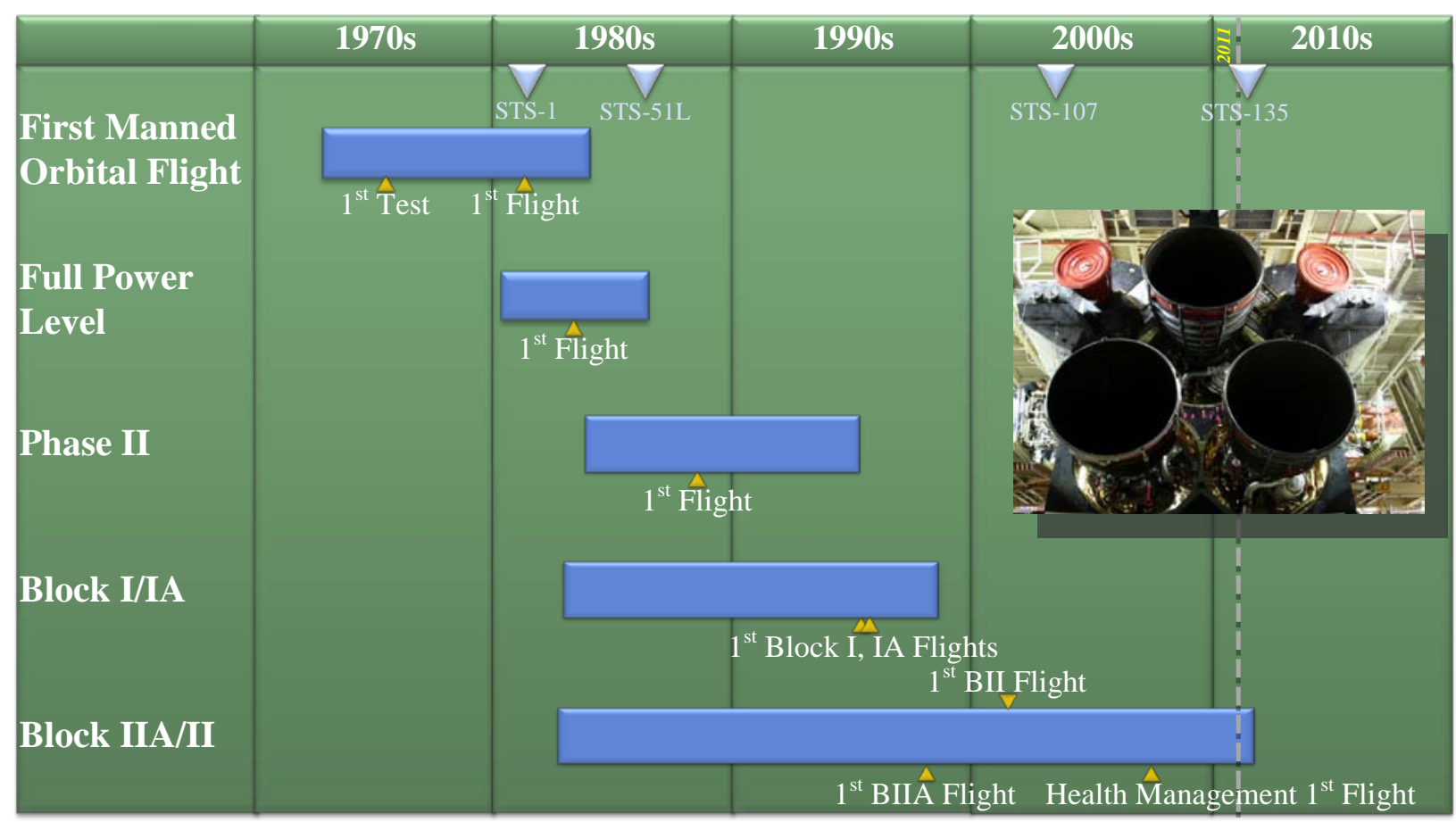

Figure 4. SSME Configuration Timeline

\section{A. First Manned Orbital Flight SSME}

The First Manned Orbital Flight (FMOF) configuration was the baseline SSME design for the first five flights of the Space Shuttle. These first Shuttle flights were intended to be the checkout phase of Space Shuttle operations. As such, engine power level was limited to $100 \%$ RPL, or 470,000 pounds vacuum thrust. The FMOF configuration met safety requirements, but many of the components had limited operational life capability and had to be replaced much sooner than the 55 flight requirement.

\section{B. Full Power Level or Phase I SSME}

There was a possibility that payloads might exist that would require operation at Full Power Level (FPL), or 109\% RPL, so within two years of the first flight, a Full Power Level or Phase I configuration was introduced into the flight program. This configuration flew from STS-6 on May 4, 1983 until the last flight of Challenger, STS-33 (51L) on January 28, 1986.

One hundred forty-seven design changes to the FMOF configuration were deemed necessary for FPL operation including changes to the powerhead (Figure 5) and, perhaps most significantly, to the four turbopumps. Changes were made to the main injector to eliminate LOX post cracking, and a steamloop was added to the nozzle feedline to eliminate a failure mode from high strains during the engine start transient. With the higher power level testing and many changes being made in the design, many failures occurred.

While the hardware and system modifications were quite successful at fixing many problems, several known failure modes and technical vulnerabilities were not addressed with the FMOF configuration. Foremost among these vulnerabilities were serious turbine blade cracks, sub-

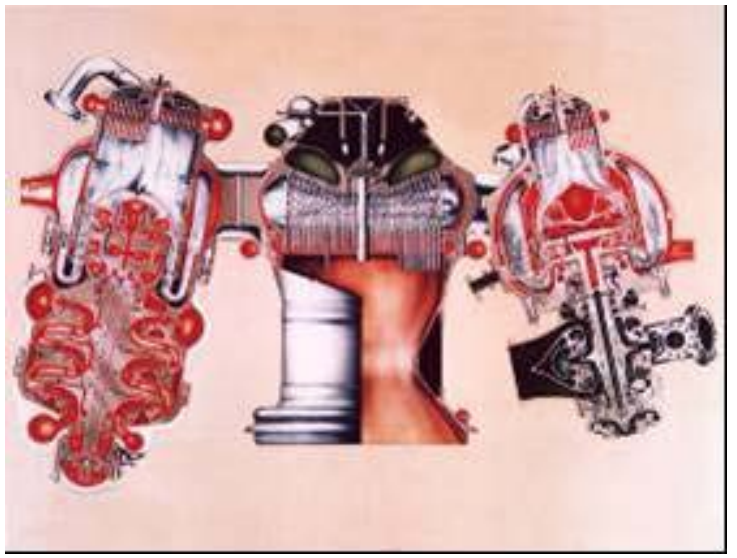

Figure 5. SSME Powerhead, Main Combustion Chamber, and High Pressure Turbopumps synchronous vibration, bearing cage delamination, and ball wear on the HPOTP. At the conclusion of the FPL 
certification program, it was decided that sufficient margins still had not been obtained to allow flight at 109\% RPL. The program restricted engine operation in flight to $104 \%$ or less and put a long term plan in place to achieve the higher operating power levels. ${ }^{1}$

\section{Phase II SSME}

Following the 1986 Challenger disaster, the entire Space Shuttle Program was re-assessed. Profound changes in SSME risk assessment and risk acceptance policies were implemented. As part of these changes, the SSME Failure Modes and Effects Analysis/Critical Items List (FMEA/CIL) was completely rewritten. The new document was more than 10 times longer than the original and identified 18 mandatory changes to the SSME hardware design, prelaunch inspection requirements, and software prior to return to flight. In addition, an SSME Margin Improvement Review Board identified 50 items as mandatory changes before returning to flight. ${ }^{1}$

The Phase II configuration was flown on the return-to-flight mission STS-26R on September 29, 1988. The new configuration included powerhead and duct changes. Significant durability improvements to high pressure turbopump blades and bearings were part of the redesign as well as a Block II main engine controller (MEC) shown in Figure 6, not to be confused with the Block II engine configuration to be described later.

HPOTP bearing problems continued to persist. Additionally, the requirements forcing extremely light weight high pressure turbomachinery made the housings, shaft, and bearing systems insufficiently rigid to withstand internal failures meaning that the turbopumps performed very well during nominal operations, but in the event that something went wrong inside them, the failure would sometimes progress rapidly to gross, uncontained turbopump and engine failure.

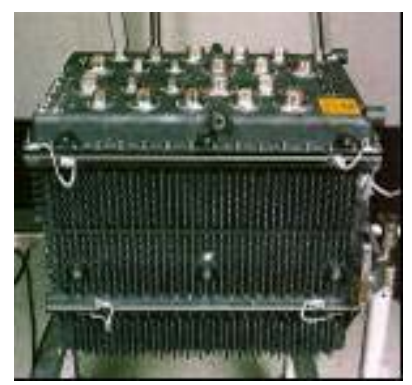

Figure 6. Block II Main Engine Controller

\section{Block I/IA SSME}

The Block I SSME introduced several upgrades to the engine, improving reliability and safety. The Phase II+ powerhead was included in the Block I and IA engine configurations and implemented a two-duct fuel-side hot-gas manifold which improved the high pressure fuel turbine discharge pressure distribution resulting in more uniform introduction of hot-gas products to the main injector, thus improving performance. As part of the redesign effort, a concerted effort was undertaken to improve the design to make it more producible. The redesigned powerhead had 52 fewer piece-parts and 74 fewer welds. The fabrication and assembly time was reduced by $40 \%$ and rework hours were reduced by almost $50 \%{ }^{1}$

A new single-tube heat exchanger (HEX) replaced the bifurcated configuration. The single-tube HEX eliminated all seven criticality 1 (would cause loss of crew and vehicle if they failed) interpropellant welds. The new HEX also had a significantly thicker wall, which made it much less susceptible to impact damage and less vulnerable to through-wall wear at the bracket interface. Prior to the redesign, the HEX was assessed as the top risk item on the SSME, primarily due to the number of critical welds, the extreme vulnerability of the thin walls, and the very rapid progression from a HEX rupture to a loss-of-vehicle failure. The redesign very successfully mitigated these concerns.

Baffles in the main injector were removed, which resulted in an efficiency gain in the engine as well as a producibility gain in the main injector. The baffles had been in place to damp out potential combustion instabilities, but were proven to be unnecessary by main injector "bomb" testing conducted during engine ground tests on the Technology Test Bed test facility at the Marshall Space Flight Center.

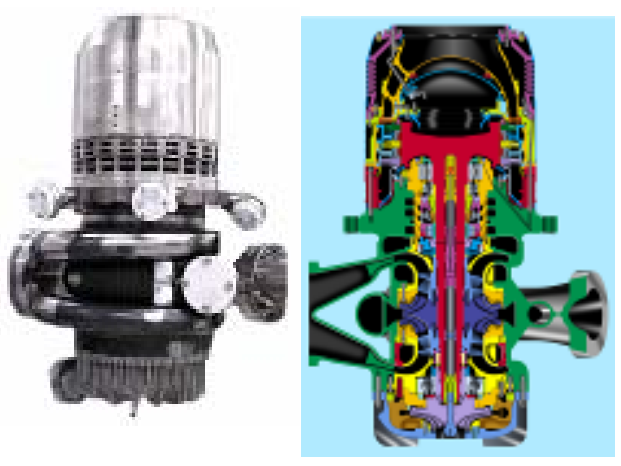


Figure 7. Block I High Pressure Oxidizer Turbopump
The Block I engine incorporated a completely new HPOTP designed under a separate contract with Pratt \& Whitney in West Palm Beach, Florida. This new turbopump was specifically designed to eliminate critical failure modes and vulnerabilities in the original HPOTP. A heavier allowable weight permitted a much stronger, stiffer rotor system, as well as more robust pump and turbine housings, which made the turbopump much more tolerant to internal failures and offnominal conditions than the previous design. Advances in casting technologies permitted the incorporation of finegrained castings in the Block I HPOTP, which allowed the elimination of 293 welds within the turbopump, including all 250 welds for which there was no rootside access for inspection at fabrication. ${ }^{1}$ Silicon nitride rolling elements were used in the pump-end bearing virtually eliminating bearing wear and fatigue concerns. Also, the turbopump was designed to use liquid hydrogen rather than liquid oxygen to cool the turbine-end bearing. Blade cracks were essentially eliminated through the use of single-crystal alloy blades with thin-walled, hollow airfoils.

The final Block I change was an upgrade to the SSME turbine discharge temperature sensors. These sensors were extremely critical to engine operation and serve as one of the few active redlines during flight. The previous design was a Resistance Temperature Device (RTD) sensor, and while it had a very fast response time, the RTD sensor was very fragile and subject to fail during operation. In fact, the only in-flight SSME premature shutdown (which led to an abort to orbit on STS-51F in 1985) was caused by a failure of the RTD temperature sensors. The sensors were upgraded to a much more robust thermocouple design.

All of these improvements resulted in an engine design capable of providing the required performance at much less risk. The first flight of a Block I SSME was on STS-70 in July 1995. Block IA incorporated all of the Block I features plus modifications to faceplate coolant holes in the main injector for increased performance. Block IA flew for the first time on STS-73 in October 1995.

\section{E. Block IIA SSME}

The Block IIA SSME implemented the Large Throat Main Combustion Chamber (LTMCC) which had been touted as the single most important SSME reliability improvement. The LTMCC increased the main chamber throat area by approximately $12 \%$ allowing the engine to operate at the same thrust level but at greatly reduced system pressures and temperatures. For most engine components, operation at 109\% RPL with a LTMCC is enveloped by operation at 104\% RPL with a standard throat MCC. Block IIA SSMEs were introduced on STS-89 in January 1998 and flew until full implementation of the Block II SSME.

The new LTMCC (Figure 8) had new features in addition to a larger throat size. Inlet and outlet manifolds were changed from welded forgings to integral castings. The cast manifolds eliminated 46 welds, including 28 criticality 1 welds. ${ }^{1}$ The manifolds were cast from JBK-75, which is not susceptible to hydrogen embrittlement; thus the time-consuming, tedious operation of copper plating the interior of the outlet manifold was eliminated. Manufacturability and production cycle time thus improved with the large throat MCC redesign.

Minor modifications were required in the LPFTP and LPOTP to better match them to the lower pressures and speeds, and silicon nitride balls were implemented in the LPOTP thrust bearing. The HPFTP received new turbine sheet metal with reduced welds, the purge-check valves incorporated filters to minimize contamination induced leakage, and the controller software was simplified. These changes addressed maintenance issues and improved operating margins. ${ }^{1}$

Similar to the temperature sensor upgrades incorporated in Block I, the SSME pressure sensors were redesigned and upgraded in Block II. The redesign reduced internal metallic contamination, which previously caused shorts and spurious signals. 


\section{F. Block II SSME}

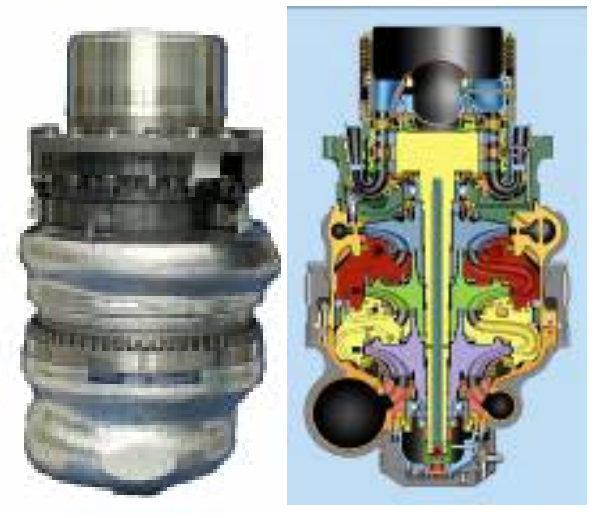

Figure 9. Block II High Pressure Fuel Turbopump
The Block II SSME added to the Block IIA design an advanced High Pressure Fuel Turbopump (Figure 9) along with miscellaneous minor changes in order to incorporate the new turbopump into the engine. Like the advanced HPOTP introduced with Block I, the Block II HPFTP was developed under a separate contract with Pratt \& Whitney in West Palm Beach, FL. It utilized state-of-the-art robust designs and materials, significantly improving the safety and reliability of the SSME.

The redesigned HPFTP incorporated improvements similar to those on the Block I HPOTP. The new HPFTP had no welds and utilized silicon nitride rolling elements in both of its bearings. It also incorporated robust, thick-walled turbine and pump housings to protect against internal failures. The additional stiffness in the shaft/bearing system reduced synchronous vibrations by factors of two to four. ${ }^{1}$ Similar to the Block I HPOTP, single crystal alloy turbine blades with thin airfoils essentially eliminated blade cracking.

By the time the alternate turbopumps were introduced into the Shuttle fleet in the mid 1990s, fracture control processes had been well defined. Parts were identified as fracture critical if their failure due to cracking would result in a catastrophic event. The fracture critical parts were inspected for pre-existing cracks, a fracture mechanics assessment was performed, materials traceability was instituted, and part-specific life limits were imposed as necessary. This combination of inspection, analysis, and life limits ensured SSME fracture critical parts were flown with confidence. ${ }^{3}$ The Block II SSME first flew on STS-104 in July 2001.

\section{G. Block II SSME with Advanced Health Management System}

Following the successful implementation of the Block II design, the Advanced Health Management System (AHMS) was added. This system utilized real-time vibration monitoring for the two high pressure turbopumps. Both turbopumps operated at high speeds, high pressures, and temperature extremes; and a flight vibration redline that could quickly detect structural failures in rotating components and shut down the engine was predicted to improve safety significantly. However, prior to the Advanced Health Management (AHM) controller, the vibration sensing system was less reliable than the turbopumps. To solve the problem of questionable sensor system data, digital signal processing hardware was incorporated into the Main Engine Controller (MEC) and advanced algorithms were developed for the software. The improvements allowed the controller to capture high pressure turbopump accelerometer data, define the frequency content, and shut down the engine if synchronous vibration levels exceeded the redlines. Advanced sensor qualification logic was also introduced to ensure the validity and accuracy of the vibration responses. Data exceeding qualification limits would cause disqualification of a sensor and could not result in an engine shutdown due to faulty data. The algorithms were validated in the lab using data from hundreds of ground tests and flights. The hardware and software was ground tested on nominal tests and also on tests where accelerometers and cables were purposefully damaged to verify the effectiveness of the algorithm to detect faulty signals and disqualify the redline.

The first AHM controller was flown in monitor-only mode on STS-116 in December 2006. The first AHM controller flown in redlines-active mode was on STS-117 in June 2007. All flights from that point on incorporated AHM controllers with redlines active. 


\section{H. Improvements in Reliability and Maintenance}

The design improvements made throughout SSME's history significantly improved reliability, reusability, and maintenance. The block changes discussed above and the implementation of AHMS culminated in a four-fold reduction in the probability of a catastrophic failure due to a SSME (Figure 10). Useable life on all components also increased significantly. Many major components were tested in excess of 100 times.

With the increases in reliability and durability of components, maintenance has also been significantly reduced. A major portion of the maintenance reduction came with the incorporation of the

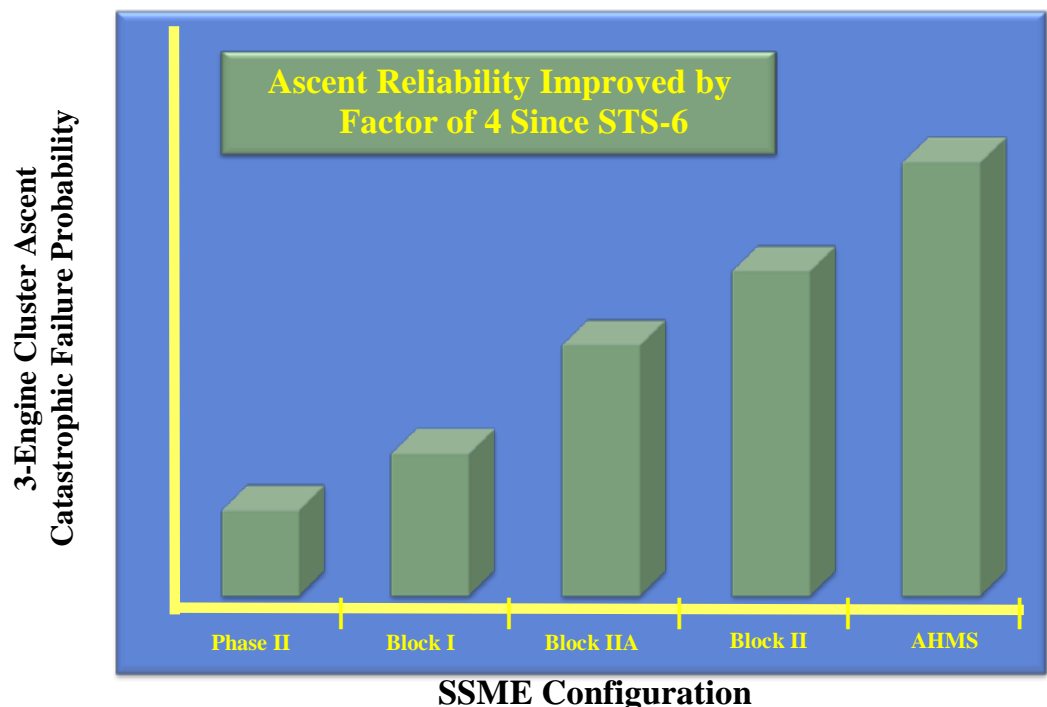

Figure 10. SSME Reliability Improvements Block I and Block II high pressure turbopumps. The turbopumps do not have to be removed after flight for inspections, eliminating a significant amount of engine disassembly and reassembly effort. The time required to inspect and prepare an engine between flights has been reduced by $57 \%$ as illustrated in Figure 11.

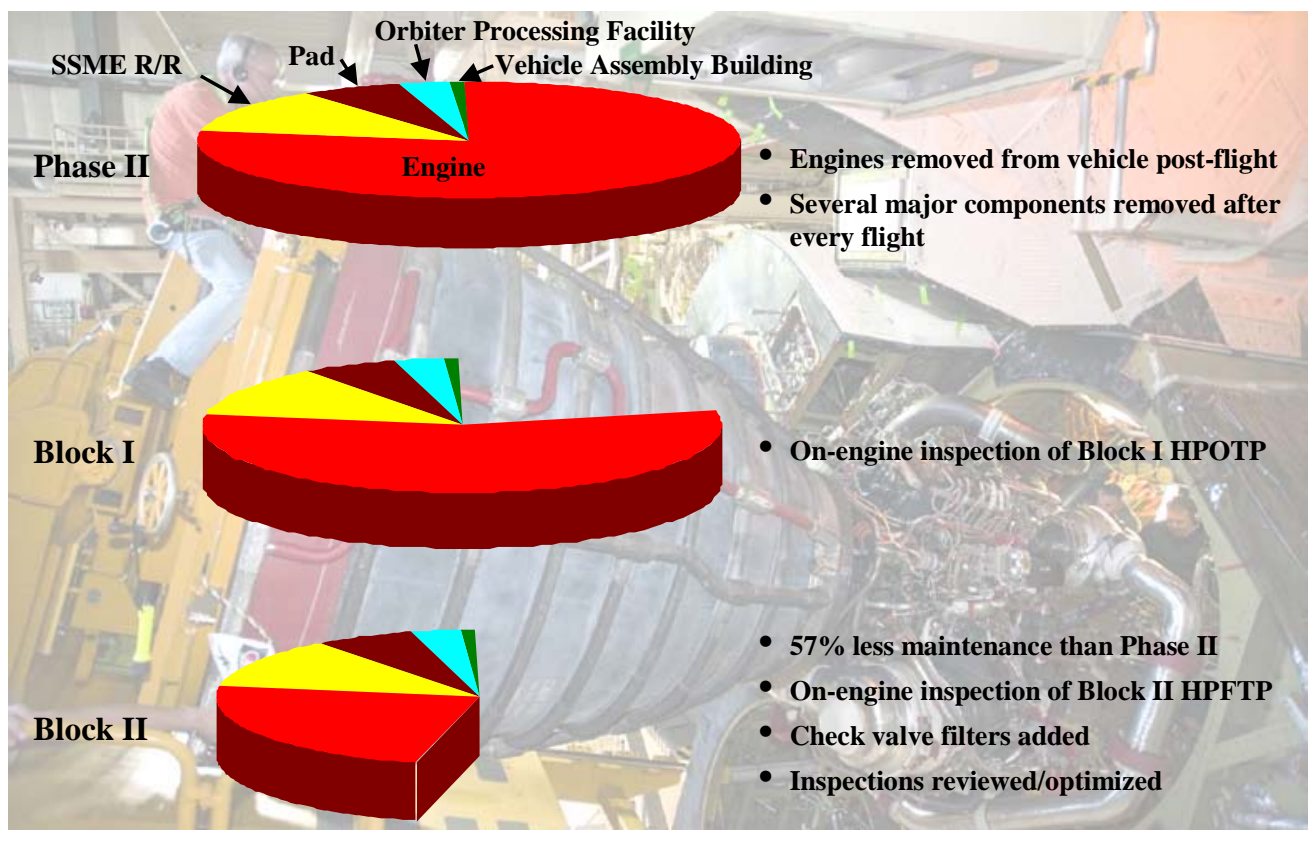

Figure 11. Maintenance Improvements Throughout SSME History

III. 


\section{Engine Assembly and Processing}

\section{A. Engine Assembly}

For the majority of the Space Shuttle Program, SSMEs were assembled at Pratt \& Whitney Rocketdyne's Canoga Park, California facility. Engines were then shipped to Stennis Space Center (SSC) for testing. Development engines remained at SSC. Flight engines were tested and, pending successful post-test inspections and a completed engine acceptance review, delivered to Kennedy Space Center where they were readied for flight. KSC personnel maintained and inspected the engines pre- and post-flight. Processing activities evolved with the program. Though originally built in Canoga Park, the set of Block I engines was recycled into either Block IIA or Block II engines at KSC. In addition, new engines built after these recycles were all assembled at KSC. All the engines either recycled or built at KSC were shipped to SSC for testing.

\section{B. Engine Post-Flight Processing}

Because the SSME was a reusable engine, inspections and maintenance were required between flights. The standard processing flow for any mission began at the end of the previous mission (Figure 12). After each landing, the Orbiter was returned to the Orbiter Processing Facility (OPF). Landings at sites other than KSC were supported by KSC personnel in order to ensure that all standard processing necessary prior to ferry flight occurred as it would have at KSC. Early in the Shuttle Program, engine maintenance was accomplished while the engines were still installed in the Orbiter's aft compartment unless an anomaly required their removal. Orbiter processing with SSMEs installed generated work conflicts in the aft compartment. Beginning with STS-26R in late 1988, SSMEs were removed after each flight. This resulted in an overall reduction in Orbiter processing flow duration. After removal, engines were moved to the SSME Processing Facility (SSMEPF) for inspections and maintenance.

Returning engines were subjected to a rigorous series of inspections documented in the Operation, Maintenance, and Requirements Specification Document. A set of standard repairs existed for many conditions. Anomalies that were found to be outside the documented set of acceptable or repairable limits were evaluated by the SSME engineering team before repair or re-use. Performance data was scrutinized by NASA and Pratt \& Whitney Rocketdyne for any anomaly that might require additional inspections or analysis. Logistics data was also scrutinized. Starts and seconds for all serialized parts were maintained in an electronic database along with applicable inspection and life limits. Following every mission, the database was checked and, if the remaining life on hardware was less than required for the subsequent mission, the applicable components were replaced. 

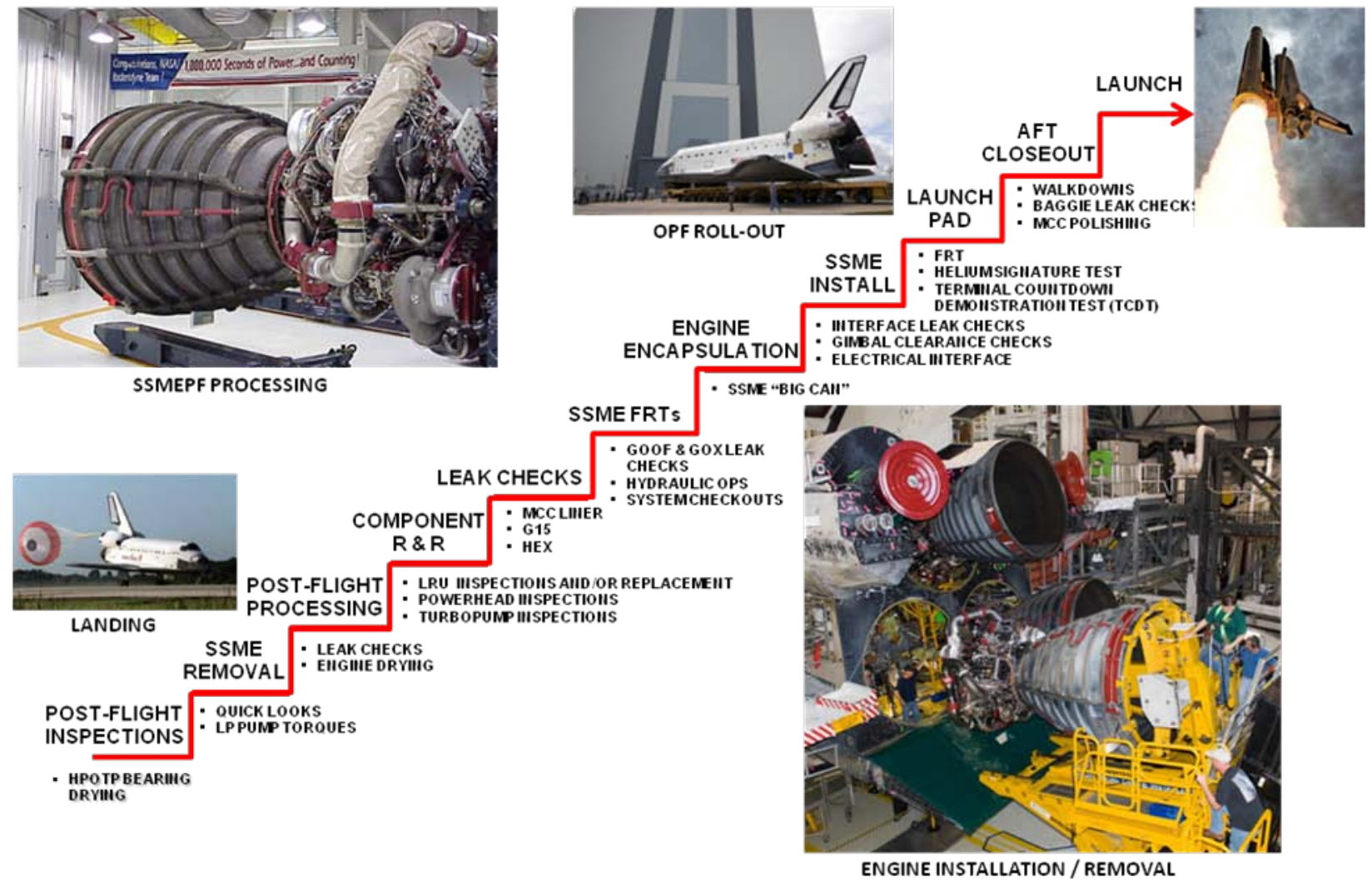

\section{Figure 12. Typical SSME Processing Flow at Kennedy Space Center}

After all required post-flight work was accomplished, the engines were moved to the OPF and installed for the next flight. Installation typically took one shift per engine. The Orbiter was eventually rolled out of the OPF and into the Vehicle Assembly Building (VAB) and stacked. Once the vehicle was secured at the Pad, Flight Readiness Tests (FRTs) were conducted on the engine to check the control system. Additional leak checks and visual inspections were performed close to launch to ensure that no collateral damage occurred to the engines during final Orbiter or vehicle work.

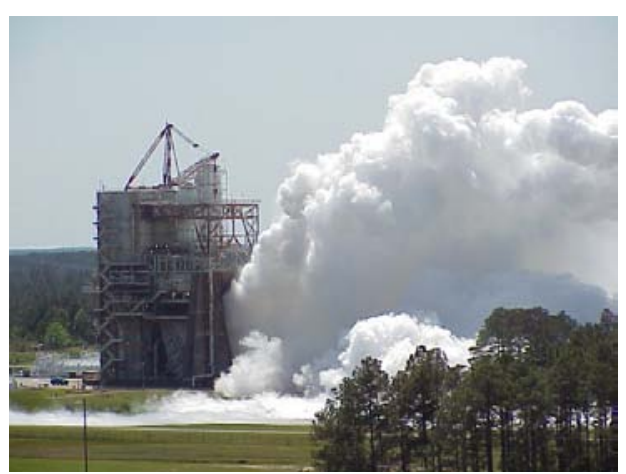

Figure 13. SSME Test at SSC

\section{Testing ${ }^{4}$}

Testing throughout the SSME program was used to develop and prove the design, understand operation, reveal failure modes, and investigate and resolve anomalies. Component level tests and rig tests of subcomponents were crucial to SSME's success and were used in many ways including developing and investigating the design of seals, investigating issues such as anomalous frequencies on impellers, demonstrating durability of bearings, and developing components like turbopumps. These smaller scale rig and component tests yielded faster and cheaper results over wider operational ranges than would have been possible with engine-level testing alone. However, it is the engine-level tests that were ultimately used as a measure of flight readiness for the engine and its components.

Throughout the SSME program, engine-level tests were conducted primarily on four test stands at Stennis Space Center (SSC) in Mississippi, though engine testing has also been done at the Rocketdyne Santa Susana Field Laboratory in California and on the Technology Test Bed (TTB) at Marshall Space Flight Center (MSFC) in Huntsville, Alabama. Engine testing began in May, 1975 at SSC and ended there in July, 2009. Engine starts and accumulated time are listed in Table 2.

American Institute of Aeronautics and Astronautics 
Table 2. SSME Operation-Starts and Seconds

\begin{tabular}{|c|c|c|}
\hline Location of Engine Hot-fires & $\underline{\text { Number of Hot-fires }}$ & Time in Operation \\
\hline A1 Test Stand at SSC & 1,007 tests & 344,458 seconds \\
\hline A2 Test Stand at SSC & 920 tests & 301,495 seconds \\
\hline B1 Test Stand at SSC & 363 tests & 165,279 seconds \\
\hline $\begin{array}{l}\text { Main Propulsion Test Article (MPTA) } \\
\text { at SSC }\end{array}$ & $\begin{array}{l}18 \text { tests of a 3-engine cluster } \\
=54 \text { hot-fires }\end{array}$ & 10,804 seconds \\
\hline A3 Test Stand at Santa Susana & 320 tests & 57,742 seconds \\
\hline $\begin{array}{c}\text { Technology Test Bed (TTB) } \\
\text { at MSFC }\end{array}$ & 66 tests & 7,939 seconds \\
\hline $\begin{array}{l}\text { Flight Readiness Firings } \\
\text { on Orbiters at KSC }\end{array}$ & $\begin{array}{l}7 \text { FRFs of a 3-engine cluster } \\
\text { = } 21 \text { hot-fires }\end{array}$ & 449 seconds \\
\hline $\begin{array}{l}\text { On-Pad Aborts } \\
\text { at KSC }\end{array}$ & $\begin{array}{c}5 \text { aborts of a 3-engine cluster } \\
=15 \text { hot-fires }\end{array}$ & 45 seconds \\
\hline Space Shuttle Launches & $\begin{array}{l}135 \text { launches of a } 3 \text {-engine cluster } \\
=405 \text { hot-fires }\end{array}$ & 207,466 seconds \\
\hline TOTAL & 3,171 hot-fires & $1,095,677$ seconds \\
\hline
\end{tabular}

SSME test objectives can be divided into development, certification, and operational tests. Some tests had objectives in multiple categories, for example sometimes certification tests of improved components occurred during operational testing of an engine configuration.

\section{A. Development Testing}

Development tests were conducted on the basic design and were used to develop safe start and shutdown transients, demonstrate mainstage operation, and evaluate the integrity of the hardware. This phase helped form the foundation of the program, demanded navigation of a very steep learning curve, and yielded results that shaped the final engine design.

The first tests were designed to develop the start sequence (Figure 14). Math models indicated propellant conditions and valve timing would be critical. It took 37 tests and 13 turbopump replacements to achieve minimum power level, which was $50 \%$ RPL at the time, and ninety-five tests to reach $100 \%$ RPL. It was late in 1978 before the first flight start sequence was finalized. ${ }^{1,2}$ During the first development tests, much was also learned regarding the processing and preparation of the engine. Pre-start thermal conditioning, purging requirements, and engine controller software for monitoring and control were established. Post-test processing such as engine drying, inspection techniques, and

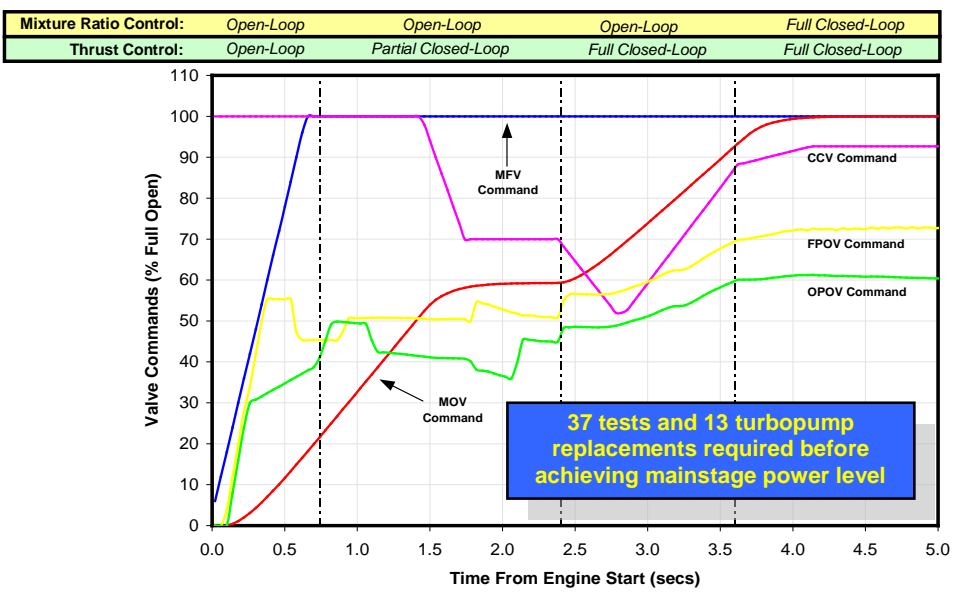

Figure 14. SSME Start Sequence leak checks were developed, which formed the foundation for future flight processing requirements.

Testing of the FMOF engine configuration continued to aggressively explore the capability of the engine and its major components. Figure 15 illustrates the problems encountered during the FMOF development history. Each problem led to insight into engine operation as well as durability, and each problem resulted in redesigns to resolve 
the issues. Engine development tests conducted during this period included tests demonstrating malfunction modes such as loss of electronic redundancies and loss of hydraulic pressure.

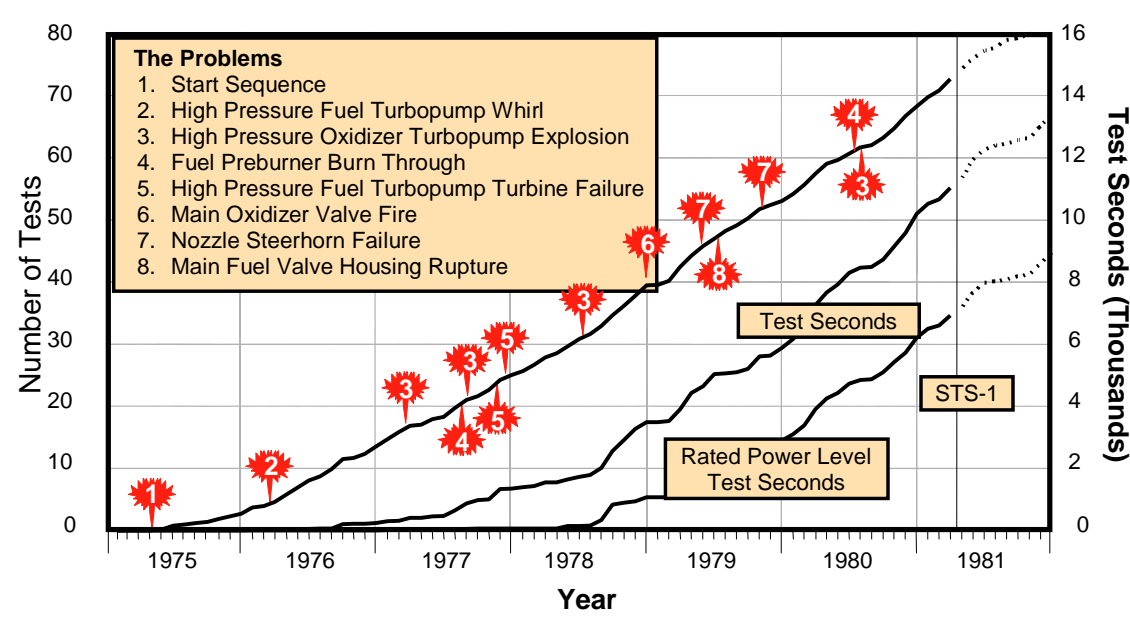

Figure 15. Development History—Tests and Problems Prior to STS-1

Also in this early part of the program, a series of tests was conducted at SSC to simulate the orbiter's aft section including a cluster of three SSMEs. The hardware accumulated to conduct these tests was dubbed the Main Propulsion Test Article (MPTA). Eighteen tests were conducted on the MPTA.

The testing that immediately followed the first Shuttle flight began to push the boundaries of engine operation. Tests were conducted for longer run times and at higher power levels leading to the certification of the Full Power Level engine and beyond. Development testing was conducted on all proposed significant upgrades incorporated into SSME throughout the Shuttle program. ${ }^{5}$

\section{B. Certification Testing}

Certification of an engine configuration involved testing multiple engine samples using aggressive test profiles that explored the boundaries of the engine-to-vehicle interface requirements. In order to gain confidence in the FMOF engine for flight, a Preliminary Flight Certification (PFC) test program was conducted prior to the first flight. Prior to STS-1, SSME had accumulated 726 starts and over 110,000 seconds.

Just as certification was required before the first flight of an engine configuration, it was also required before the flight of any design change. In some cases, small changes to hardware were certified by similarity to the previous design of the part or by analysis. Significant changes often required certification tests.

The number of tests required, test profiles, and test durations included in a certification plan depended on the complexity or extent of the changes being incorporated into the baseline design. For example, one change to Liquid Air Insulation required only one certification engine test. The advent of the Block II HPFTP required a certification series of twenty-two tests on each of two samples.

Typically, certification tests were designed to exercise the boundaries of operation expected in flight so that as many conditions as possible are experienced for the first time in a ground test rather than in flight. Since design changes were incorporated periodically throughout SSME's history, certification tests were almost continually a part of SSME's testing program and were essential in proving the flight-worthiness of all SSME hardware.

\section{Operational Testing}

Operational testing was conducted on hardware designs already approved for flight. Every major component on every SSME was acceptance tested prior to flight. Additional reasons for conducting tests on production hardware are below.

\section{Issues Affecting Single Components or Engines}

There were many issues that only affected specific parts. For example, hardware discrepancies that occurred during fabrication on individual parts sometimes were discovered during an acceptance test. Often, the replacement of hardware required another test to ensure the problem was fixed. Additionally, repairs or processing escapes occurred that required testing before continued flight use. For example, unique post-flight Nozzle tube repairs sometimes required testing before returning to flight.

2. Issues Affecting All Units of a Given Component

Sometimes problems were discovered that called into questions the integrity of the whole fleet of a component. If the fleet was life limited to something less than required to meet the flight manifest, all units were rebuilt and reacceptance tested. For example, a generic issue with the manufacturing of a filter internal to the Main Engine Controller forced all units to be life-limited, rebuilt with replacement filters, and re-acceptance tested. 
3. In-Flight Anomaly Resolution, Investigation of a Ground-Observed Issue, and Development of Flight Rationale

Quite often, tests on production designs were required to investigate issues and resolve anomalies that did not appear during development or certification. Sometimes these anomalies occurred due to the number of cycles on the hardware being tested and therefore appeared after the development phase. On other occasions, they appeared during production because they were related to specific stack-ups of tolerances or environments that had not occurred previously. The SSME was reusable, and statistically significant numbers of them were not built. It was impossible to test every combination of tolerances, even in one component, prior to flight. Occasionally issues arose for which analysis alone could not provide flight rationale, whether the issue was discovered on the ground or in flight, and tests are required. When anomalies occurred during a flight, the ensuing investigation often resulted in a requirement for ground tests to be conducted.

4. Vehicle Issues

Vehicle issues sometimes impact or implicate SSME and require ground testing for resolution. For example, when inspection of orbiter MPS flowliners in 2002 found cracks just upstream of the inlet to the Low Pressure Fuel Turbopump (LPFTP), several subcomponent tests were conducted to investigate the interactions between the engine and vehicle. In addition, modifications were made to engine test stands so that the problem could be further investigated. The test results were used to set limits on operational speeds of the LPFTPs so as to refrain from operating in a high order cavitation regime detrimental to vehicle hardware. It was also discovered during this time that the same high order cavitation that affected upstream hardware also interfered with predicted blade modes in the LPFTP, so the operational placards protected both sides of the interface.

5. Flight Rule Changes and Demonstration

Flight Rule demonstration was needed to support potential changes and was sometimes requested because conditions had never been previously run.

6. Off-Nominal Testing

Off-nominal testing was used throughout SSME's history as a method of providing more extensive knowledge of how the engine operates and as a tool for determining margins against undesirable conditions. These tests generally incurred more risk since the engine was being pushed outside its normal operating envelope. A great deal of analysis, planning, and coordination was required to ensure the tests were conducted successfully and safely. Offnominal tests included those designed to explore structural and performance margins, verify fail-operational (failop)/fail-safe conditions, expand the launch criteria envelope, test the limits of ICD requirements, demonstrate operation at redline limits, examine the effects of process creep, demonstrate the durability of hardware with known flaws, and expose issues that could be related to the accumulation of starts and/or seconds of operation. Malfunctions at every stage of the launch: chill, start, mainstage, and shutdown were purposely introduced in ground tests. Off-nominal tests included chill bleed interruptions, reduced chill-flow rate, purge interruptions, controller fail-op/fail-safe demonstrations such as controller major cycle restarts and controller channel switch-over. ${ }^{2}$ Additionally, tests to simulate an SSME application for upper stage were conducted. In every case the engines performed safely and as expected.

\section{Testing Summary and Conclusions}

Testing was an integral part of the SSME project and was critical in the success of the Shuttle Program. Tests were conducted on this engine for more than thirty years and made it a very well-understood liquid rocket engine in spite of its complexity. Testing was used to develop the engine, to expand operating envelopes, to investigate and resolve anomalies, and to implement design changes that added to the durability and operational envelope of the engine.

Many problems were discovered through extensive testing. Sometimes design changes that seemed small were found to have adverse impacts large enough to cause major failures. Conversely, sometimes design changes thought to be large and significant proved to be improvements at their first implementation. Without testing, the effects of modifications to systems as complex as SSME are impossible to accurately determine.

While the benefits of testing are obvious at the onset of an engine development program, it is sometimes less obvious how important maintaining an active test program is in the production portion of a program. SSME used engine testing many times near the close of the program to develop flight rationale. Additionally, several large problems did not present themselves until late in production which, without an active test program, would have proved exceedingly difficult if not impossible to overcome. 


\section{Benefits of a Long Program, Testing, and Reusability}

SSME used its strong engine test program to find problems on the ground in order to prevent encountering them in flight. While several anomalies were noted during ascent, the engines operated safely and successfully on every flight. In addition to testing, another reason for this was the benefit of flying a reusable engine. Reusability forced long duration testing on the ground (every design was allowed to fly only $50 \%$ as long as it had been tested) and inspections of returning hardware. Environments can be predicted and, to a degree, measured with instrumentation, but post-flight inspections offered insight into exactly how each part behaved. Measurable improvements throughout the history of the program have been observed in the reduction of launch delays as illustrated in Figure 16. The more the SSME team strove to understand its hardware through extensive testing and inspections, the more they tried to improve it, and the safer it got. The final 63 consecutive launches occurred without an SSME-related delay.

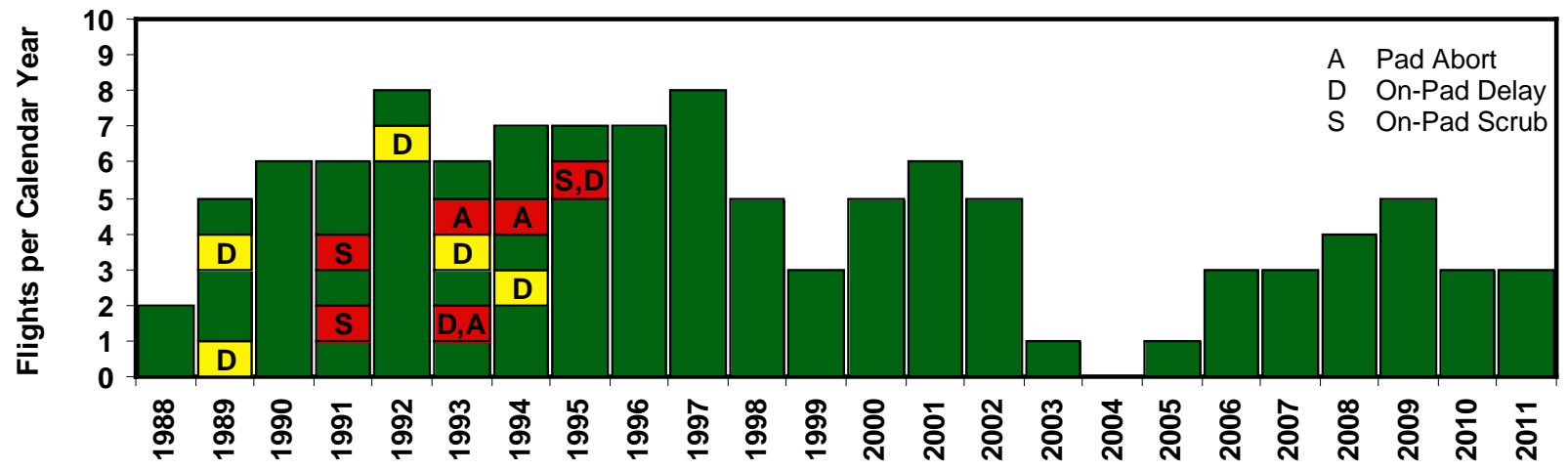

Figure 16. Launch Delays Due to SSME Throughout the History of the Program

This greater understanding and improved design of the engine also resulted in a decline in major engine ground test incidents. Figure 17 illustrates the total seconds of the SSME test program and the number of incidents over the years of operation.

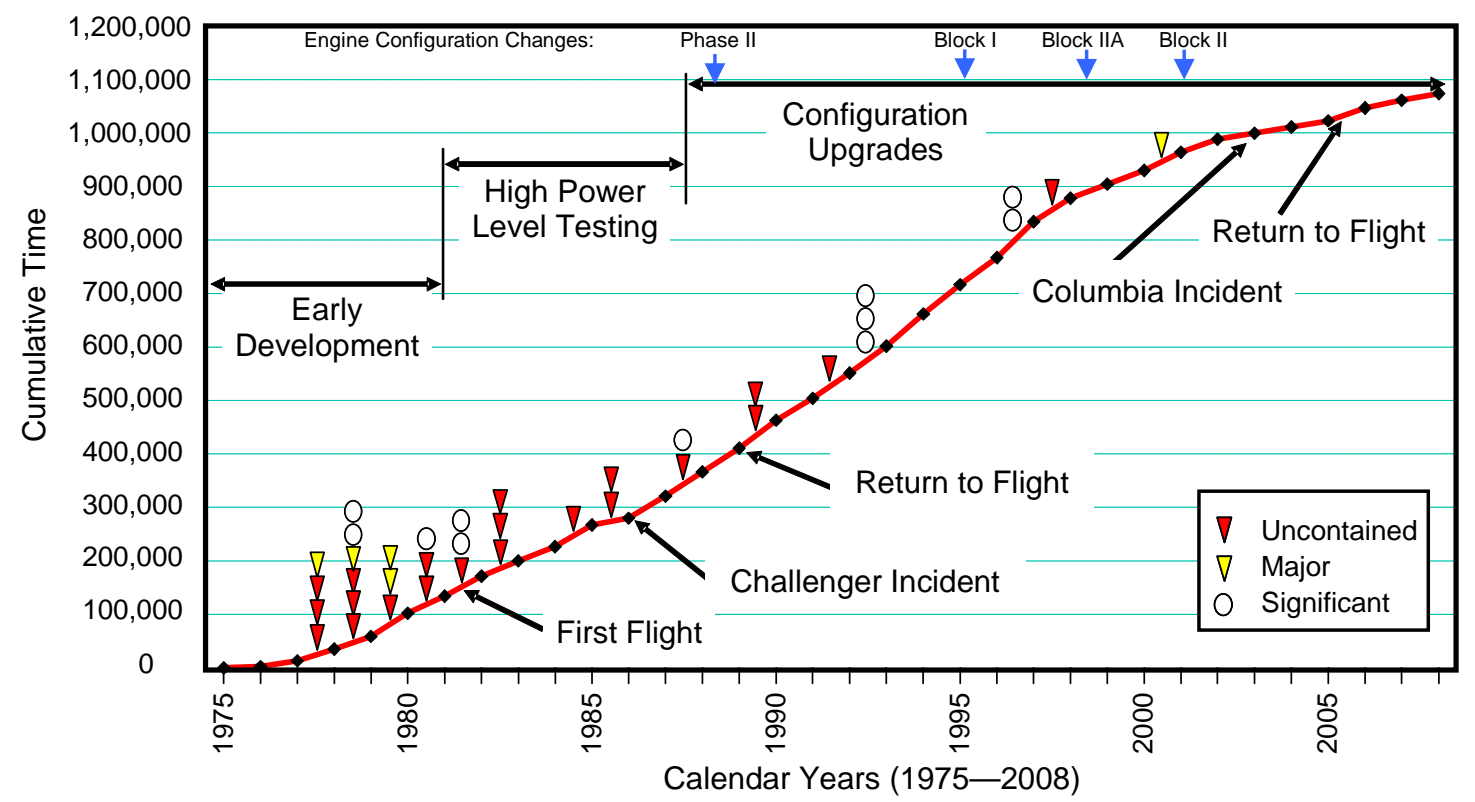

Figure 17. Incident Occurrences Throughout SSME's History

Shuttle flight success was not the only outcome of the amazing history SSME enjoyed. Engineering profited as well. Many engineering disciplines were required to achieve and maintain SSME's success. SSME in return was 
responsible for the advancement in the state of the art in many engineering disciplines. For example, in fluid dynamics, extensive work was conducted understanding cavitation and increasing the abilities to model it; in structural dynamics, knowledge was gained in finite element prediction techniques, data acquisition techniques, and structural dynamics of extremely high frequency responses; in rotordynamics, better models exist to predict instability, synchronous responses, and external loading; in materials, continuous improvements were made in materials characterization and processing for reliability, performance, producibility, and reduced cost.

\section{Conclusion}

The Space Shuttle Main Engine is the most technologically-advanced, high-performance rocket engine ever produced. SSMEs successfully launched 135 Space Shuttle missions and accrued over one million seconds of hotfire time during ground tests and flight operation, more than any other large rocket engine, with a demonstrated engine reliability in excess of 0.9995 . The SSME was instrumental in material characterization and has advanced the state of the art in several engineering disciplines. The extensive ground test program, multiple flights, and the ability to inspect the hardware after tests and flights made the SSME arguably the most well-understood rocket engine in history. The experience gained during the evolution of the SSME program forms a fundamental foundation of liquid propulsion knowledge to benefit all future endeavors.

\section{Acknowledgments}

The authors would like to thank Jerry Cook, Steve Wofford, Fred Jue, Philip Benefield, Lewis Maddux, and Ken Kan for their 2010 JANNAF Liquid Propulsion Conference papers documenting the evolution, operation, and testing of the SSME. The JANNAF papers listed in the References section were used extensively throughout this paper.

The authors also gratefully acknowledge the accomplishments of the many people across the country and internationally who have been involved in designing, manufacturing, developing, testing, analyzing, and producing the SSME throughout its history, and they are immensely thankful to have had the opportunity to participate in such a historic achievement. In one paper, it is impossible to fully cover the rich history or the many lessons that have been learned from SSME.

\section{References}

${ }^{1}$ Biggs, Robert E. Space Shuttle Main Engine: The First Twenty Years and Beyond. American Astronautical Society History Series, Volume 29. Univelt for American Astronautical Society, San Diego, CA, 2008.

${ }^{2}$ Bradley, Douglas P. and Philip A. Benefield. “Space Shuttle Main Engine Operational Capability.” 57th Joint Army-NavyNASA-Air Force Propulsion Meeting / 5th Liquid Propulsion Subcommittee Meeting. Colorado Springs, CO. May 3-7, 2010.

${ }^{3}$ Hale, Wayne, Katherine Van Hooser, Greg Swanson, Ph.D, et al. Wings in Orbit: Scientific and Engineering Legacies of the Space Shuttle. NASA/SP-2010-3409. U. S. Government Printing Office, Washington, D.C., 2010. Page 285.

${ }^{4}$ Van Hooser, Katherine P., Lewis J. Maddux, and Ken Kan. "History and Benefits of Engine Level Testing Throughout the Space Shuttle Main Engine Program.” 57th Joint Army-Navy-NASA-Air Force Propulsion Meeting / 5th Liquid Propulsion Subcommittee Meeting. Colorado Springs, CO. May 3-7, 2010.

${ }^{5}$ Wofford, Steven J., Fred Jue, and Jerry R. Cook. "Space Shuttle Main Engine Design Evolution.” 57th Joint Army-NavyNASA-Air Force Propulsion Meeting / 5th Liquid Propulsion Subcommittee Meeting. Colorado Springs, CO. May 3-7, 2010. 


\section{Space Shuttle Main Engine -}

\section{The Relentless Pursuit of Improvement}

Katherine Van Hooser

SSME Chief Engineer

NASA Marshall Space Flight Center

Huntsville, AL
Douglas P. Bradley

SSME Chief Engineer

Pratt \& Whitney Rocketdyne

Canoga Park, CA 


\section{Space Shuttle Main Engine (SSME) Relentless Pursuit of Improvement}

- SSME 101

- Design evolution

- Verification by ground test

- Analytical tool evolution

- Lessons 


\section{SSME is the First Reusable Large Liquid Rocket Engine}

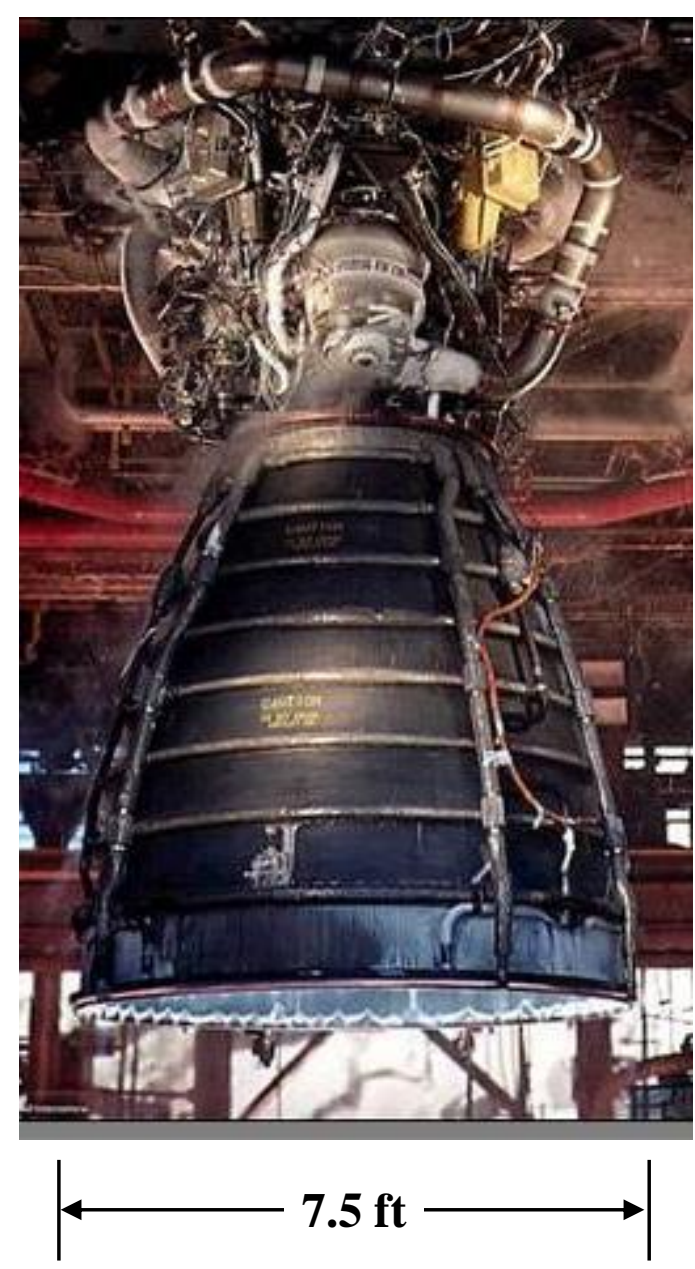

Pratt \& Whitney Rocketdyne
Propellants

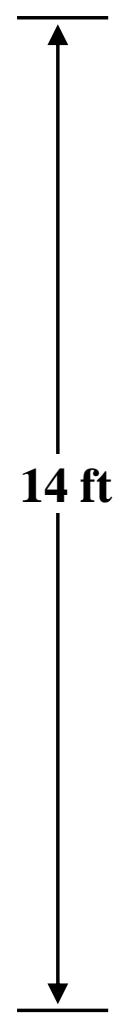

Total program hot-fire time
Service life

Gimbal range

Weight
02/H2

$469,448 \mathrm{lb}$

$490,847 \mathrm{lb}$

$512,271 \mathrm{lb}$

2,994 psia

$452 \mathrm{sec}$

67 to 109

$+/-11^{\circ}$

$7,748 \mathrm{lb}$

55 flights 27,000 seconds

3,171 starts $1,095,677$ seconds 


\section{High Performance Staged Combustion Cycle}

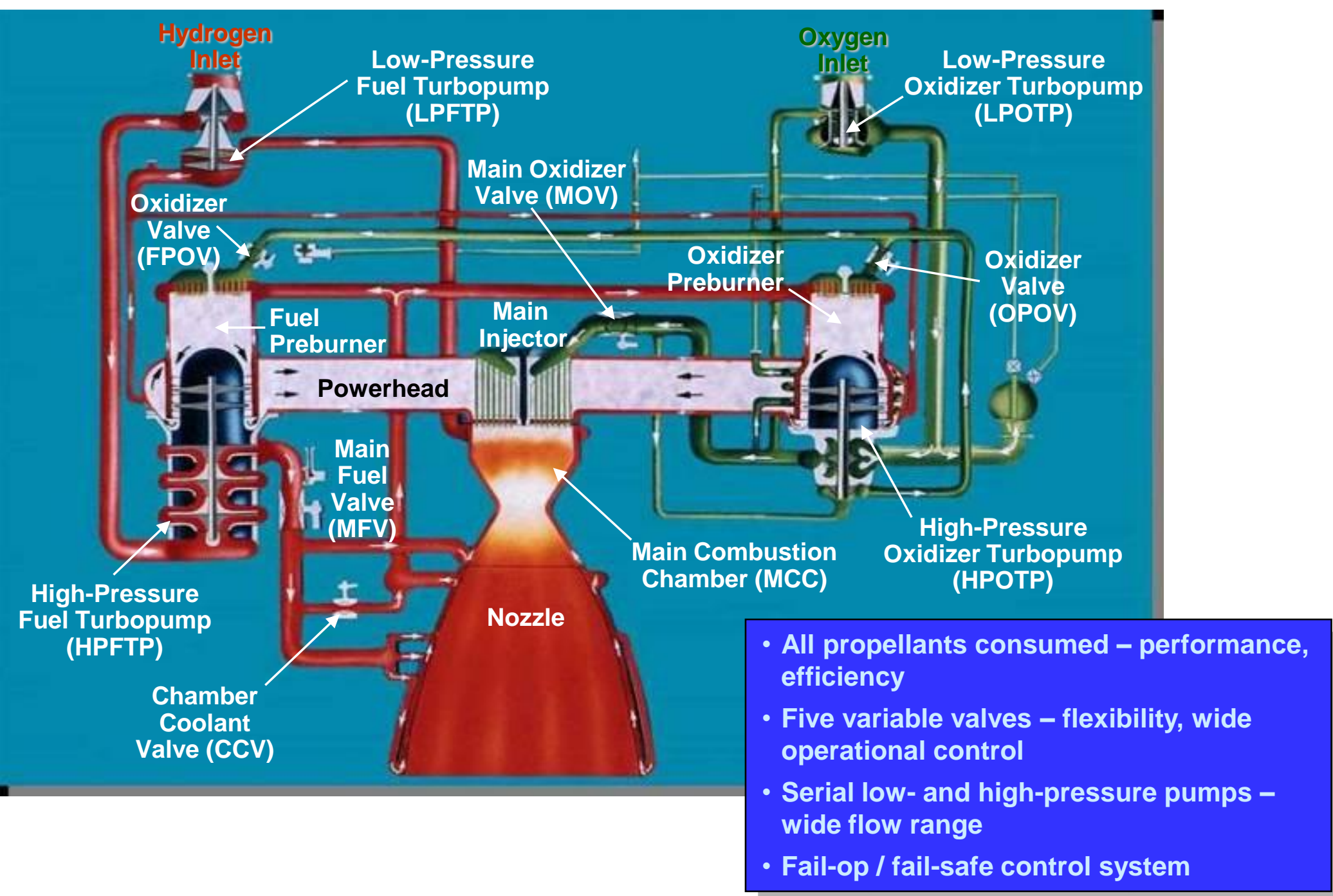




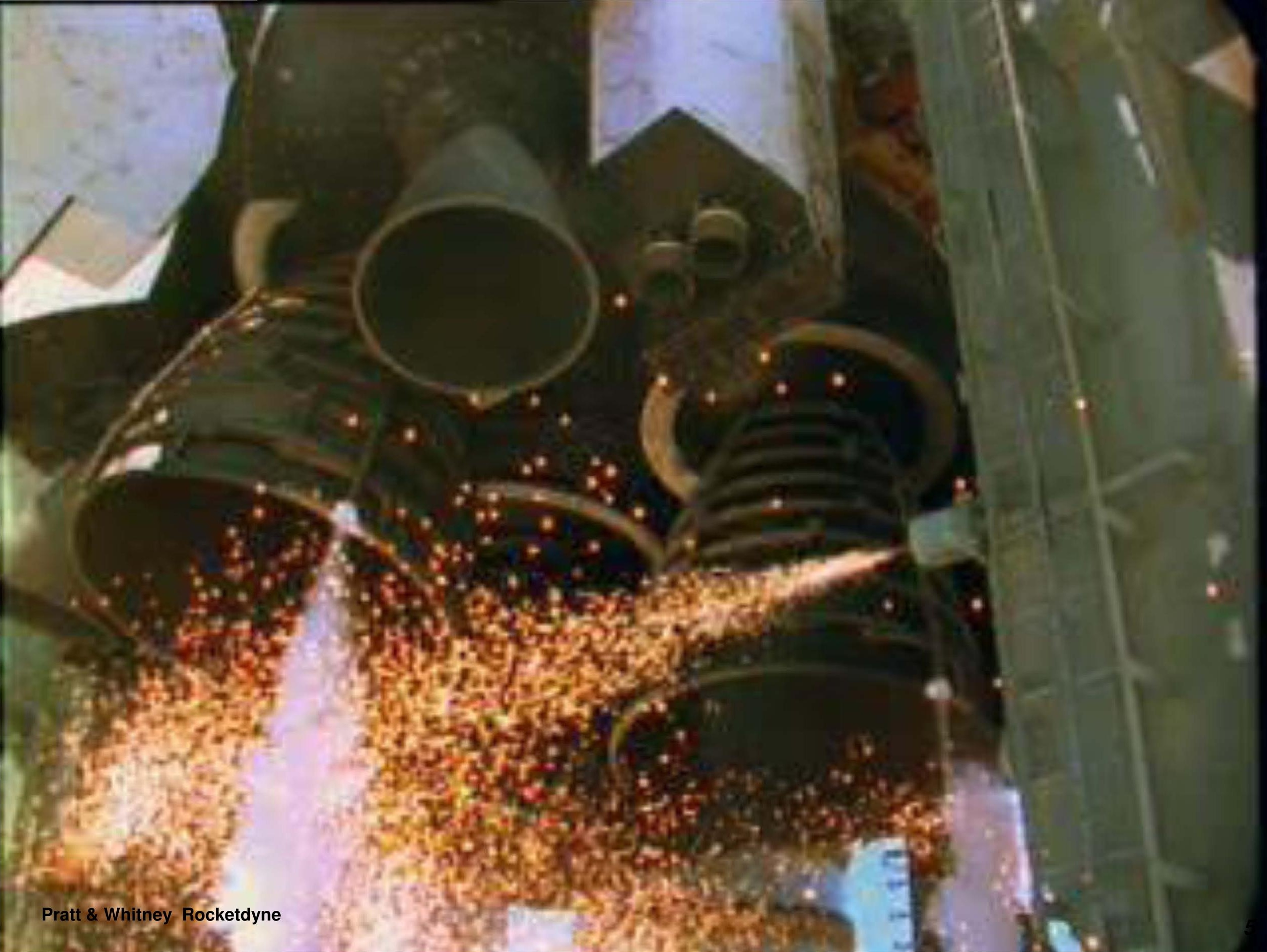




\section{SSME Block Improvements Timeline}

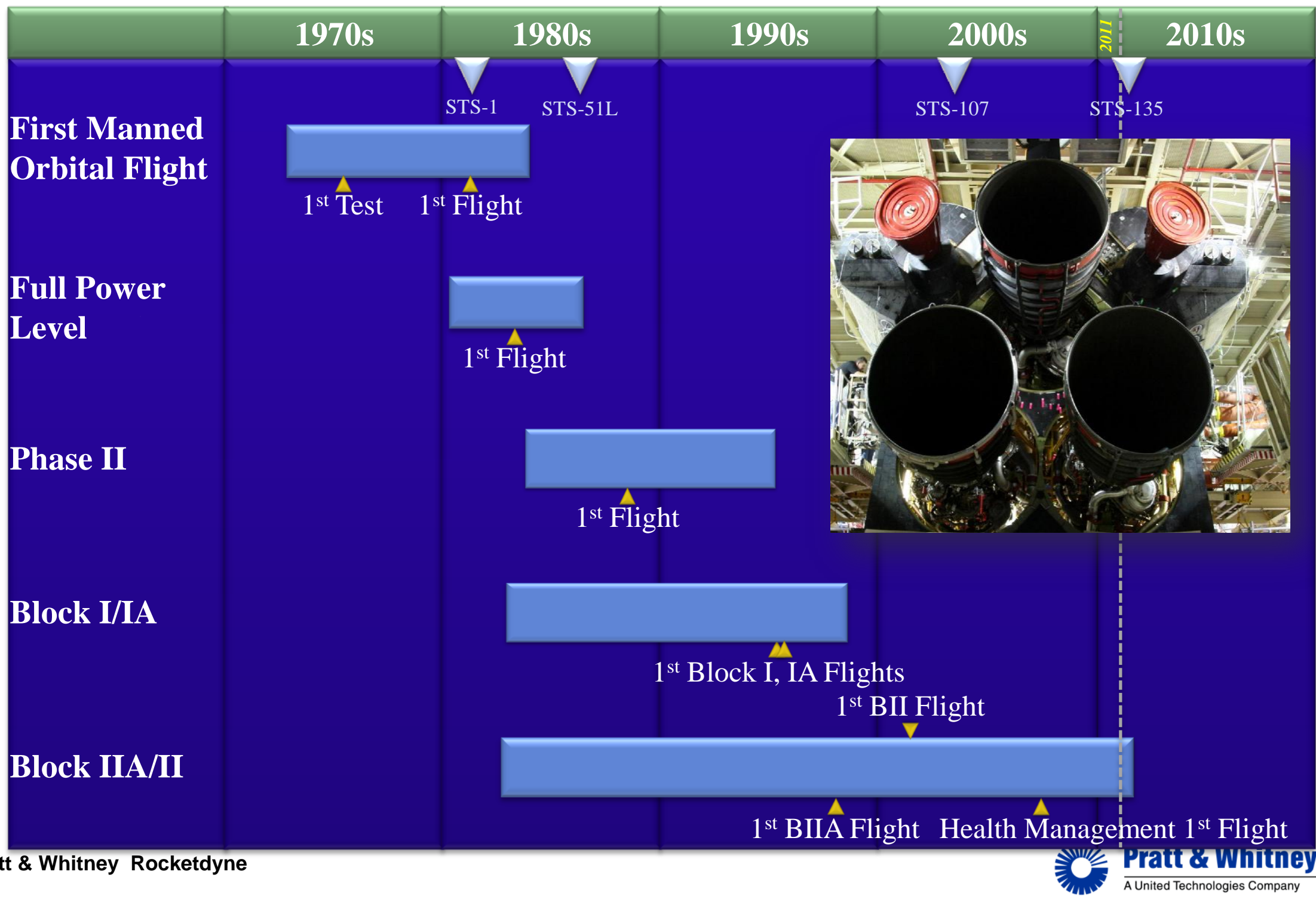




\section{Full Power Level (Phase I) SSME First Flight - April 1983}

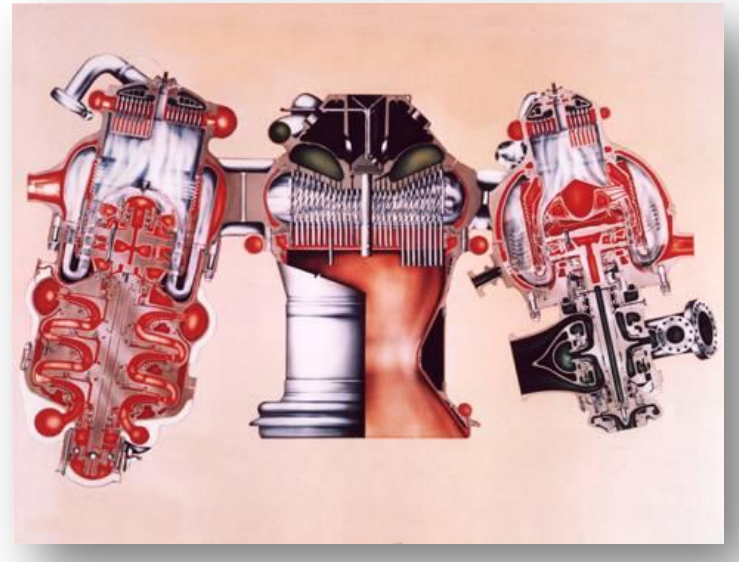

\section{Powerhead}

- Changes to Hot Gas Manifold fuel bowl liner, lox posts in Fuel Preburner

- New flow meter straightener

- Lox post shields HPFTP

- Kel-F seals

- Smooth interstage seals

- Increased turbine blade tip clearances HPOTP

- Housing material changed

Pratt \& Whitney Rocketdyne

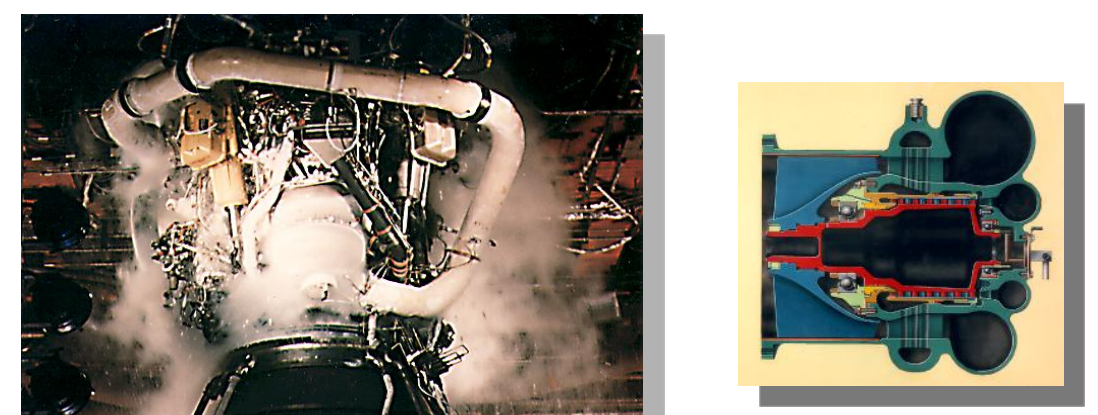

Low Pressure Oxidizer Turbopump

- Turbine discharge turning vane mod

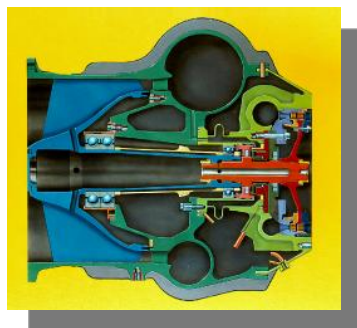

Low Pressure Fuel Turbopump

- Revised blocking area

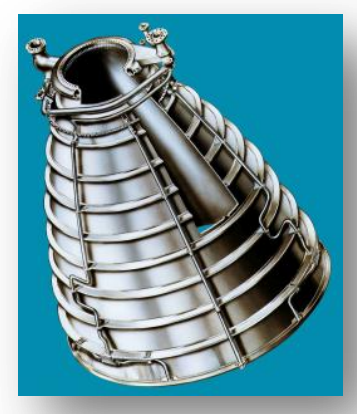

Nozzle

- $\quad 1^{\text {st }}$ Flight STS-6 (April 1983)

- 147 Required Changes from Baseline Engine Incorporated to Enable Operation at $109 \%$ Power Level
- Increased tube wall thickness

- Added steam loop 


\section{Phase II SSME First Flight - September 1988}

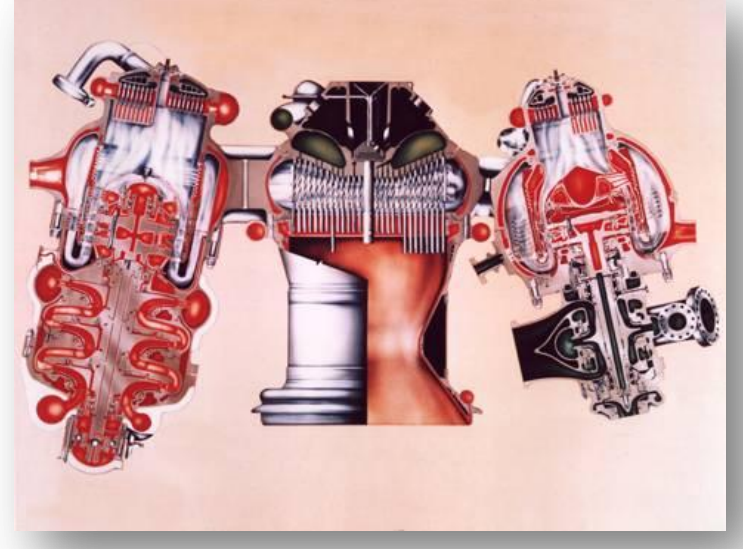

\section{Powerhead}

- Main Injector oxidizer inlet vane rework MCC

- EDNi reinforced outlet neck HPTPS

- Desensitize coolant system

- Bearing and blade improvements

- Rotor stability

Ducts

- Low Pressure Fuel Duct helium barrier

Pratt \& Whitney Rocketdyne

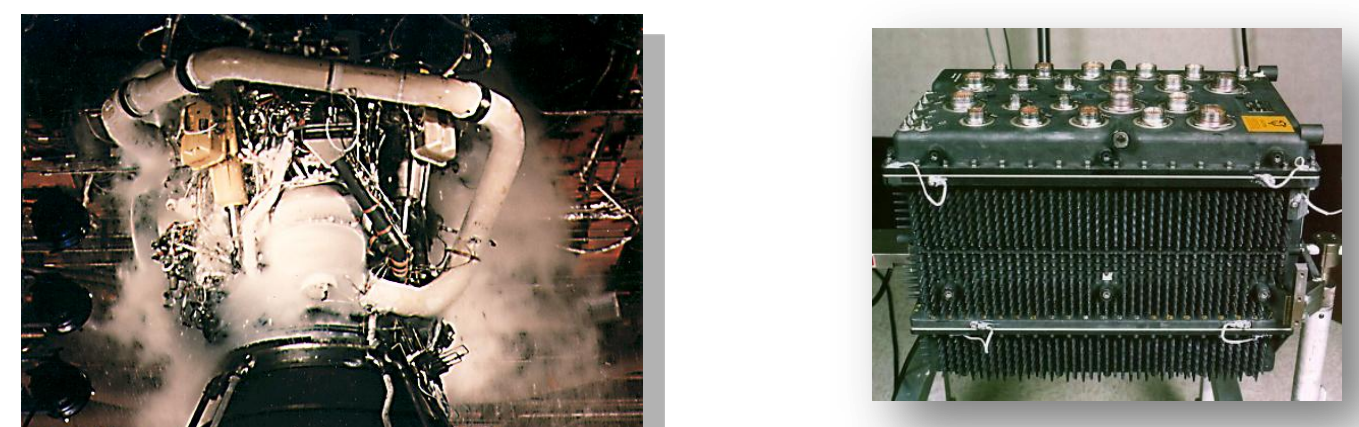

Block II Controller

- New type and increased memory

- Improved producibility and maintainability

- High order language for software

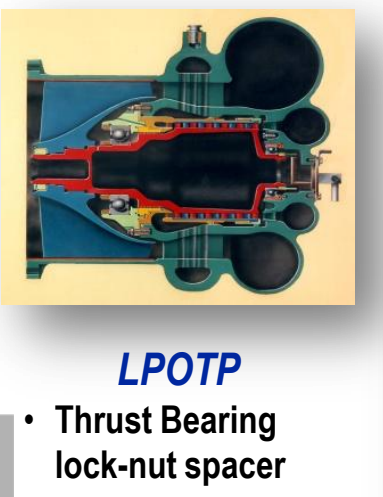

- Fully Recertified to $104 \%$ RPL

- 0.9994 Demonstrated High Reliability

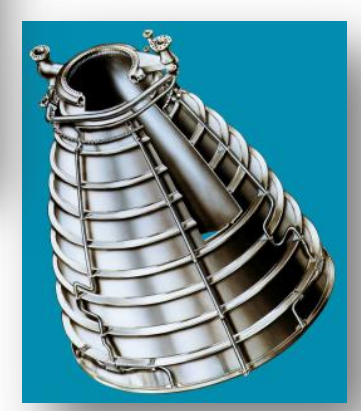

Nozzle

- Added insulation to aft manifold and drain lines

Pratt \& Whitney 


\section{Block I SSME \\ First Flight - July 1995}

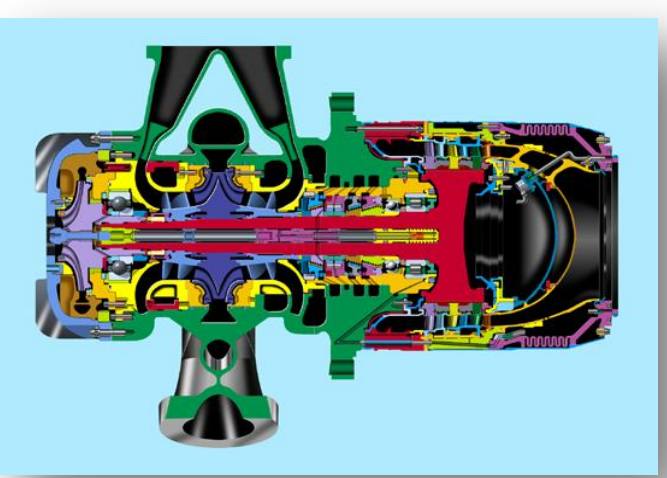

Alternate High Pressure

Oxidizer Turbopump

- Precision castings

- Ceramic bearing balls

- Eliminated seal pressure redline

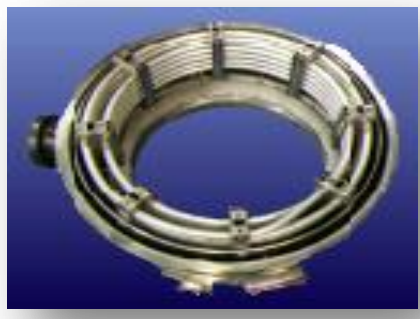

Single Tube Heat Exchanger

- Eliminated all 7 criticality 1

interpropellant welds

- FOD tolerant $25 \%$ thicker tubes

- Low maintenance

Pratt \& Whitney Rocketdyne

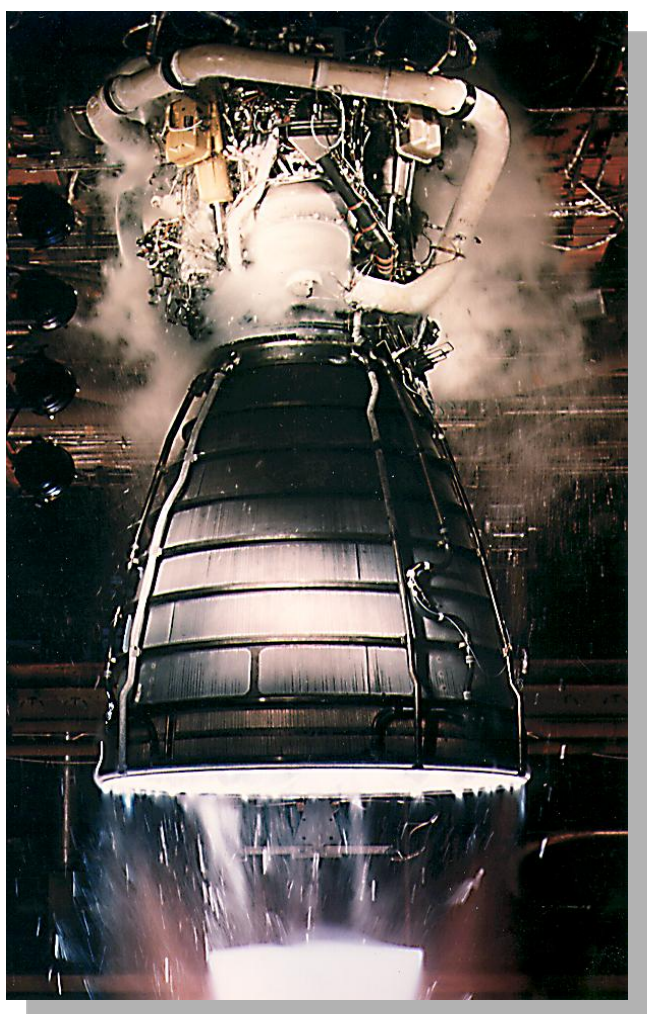

- $\quad 1^{\text {st }}$ Flight STS-70

- Improved Safety, Reliability, \& Operability

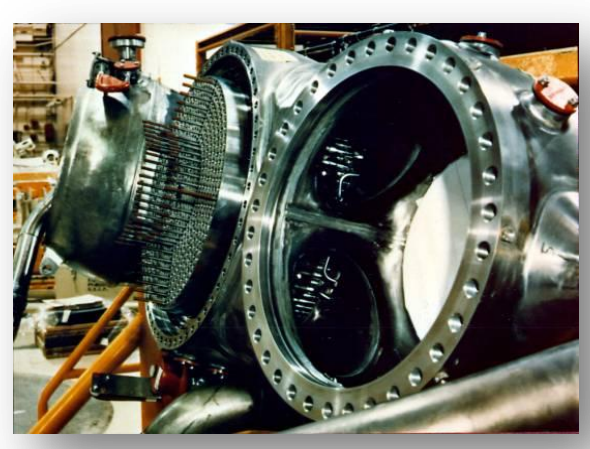

Two-Duct Powerhead

- Improved liner and injector life

- Baffleless main injector

- Thick, cut-back turning vanes

- Eliminated 74 welds

- Part count reduced by 52

- Cycle time reduced $40 \%$

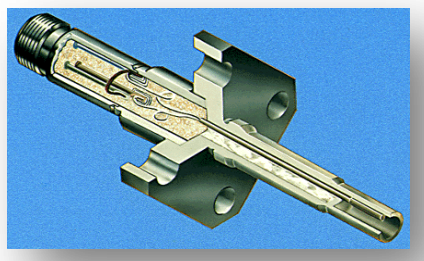

Hot Gas Temp Sensors

- Improved reliability 


\section{Block IIA SSME First Flight - January 1998}

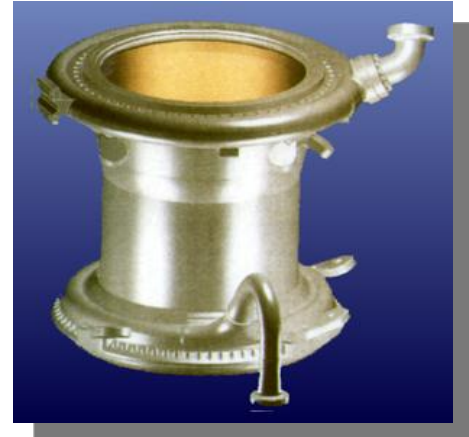

Large Throat Main Combustion Chamber

- Engine pressure \& temperatures reduced up to $10 \%$

- Increased channel wall cooling

- Simple cast manifolds, eliminated 52 welds

- Cost \& cycle time reduction over $50 \%$

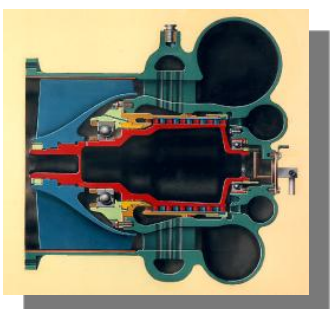

Low Pressure Oxidizer

Turbopump

- Ceramic bearing balls

- Robust rotor

- Increased

performance inducer alignment

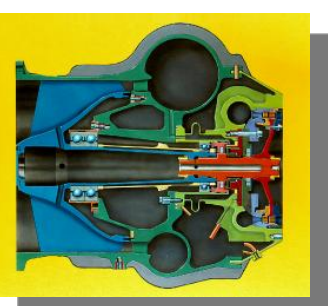

Low Pressure Fuel

Turbopump

- Kevlar jacket insulation

- Reblocked nozzle

- Eliminated plug weld

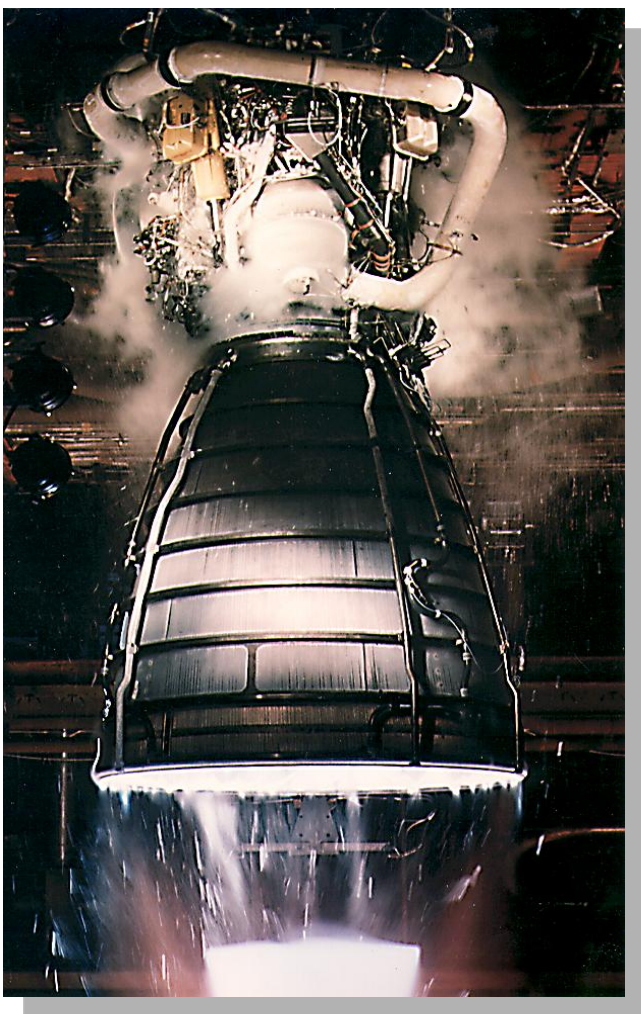

- $1^{\text {st }}$ Flight STS-89

- >2x Reliability Improvement

- Certified to $\mathbf{1 0 4 . 5 \%}$ Nominal Thrust

- Improved Safety, Life, \& Operability

- Reduced Cost

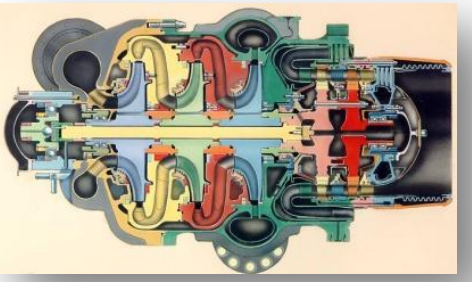

High Pressure Fuel Turbopump

- One-piece EDM turbine inlet

- Increased life turbine blades

- Improved rotor balance

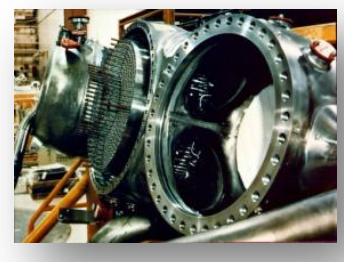

Main Injector Specific Impulse Modifications

- Eliminated parasitic hydrogen losses $0.4 \mathrm{sec}$ Isp recovery

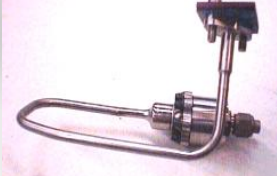

Purge Check Valves

- Added upstream Filters

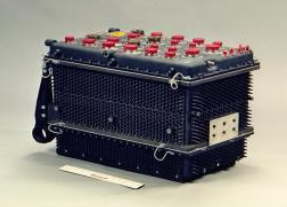

Software

- Self-calibrating actuators

- Nominal coefficients

- Improved logic

- Increased redundancy thermocouples

\section{Pratt \& Whitney Rocketdyne}




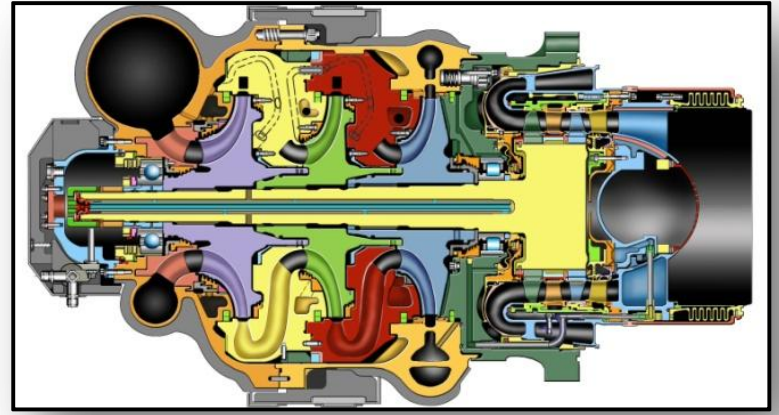

Block II High Pressure

Fuel Turbopump

- Improved turbine blade fatigue capability

- Robust turbine housing

- Pump Inlet Housing burst margin increased

- Stiffer/heavier rotor

- Robust hybrid bearing systems

- Extensive use of precision investment castings

- Coolant liner redline eliminated

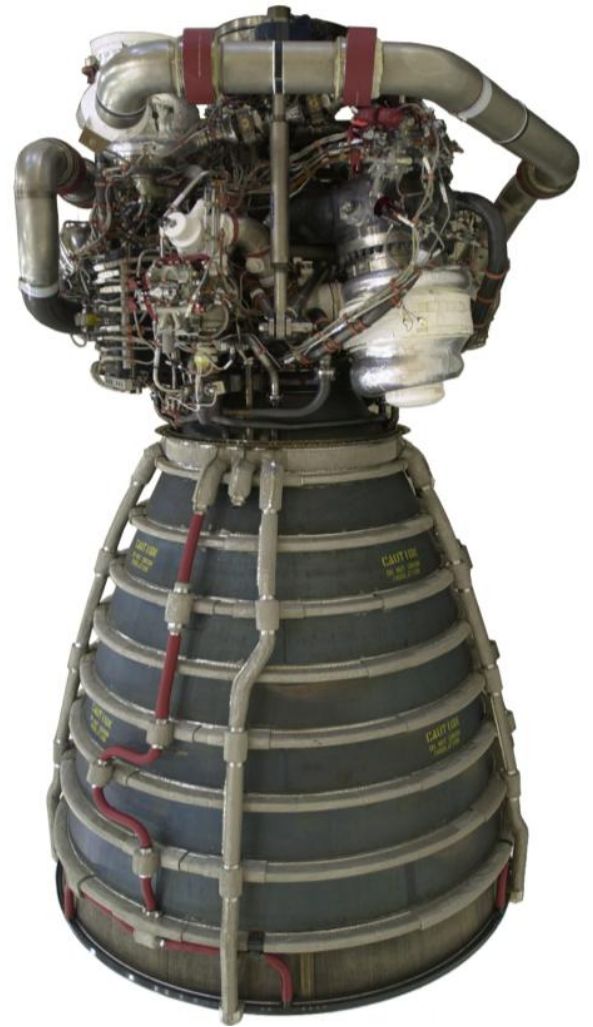

- $1^{\text {st }}$ Flight STS-104

- AHMS $1^{\text {st }}$ Flight STS-117 (June 2007)

- Improved System Reliability, Operability, \& Safety

- Goal of 10 Missions Between Overhauls

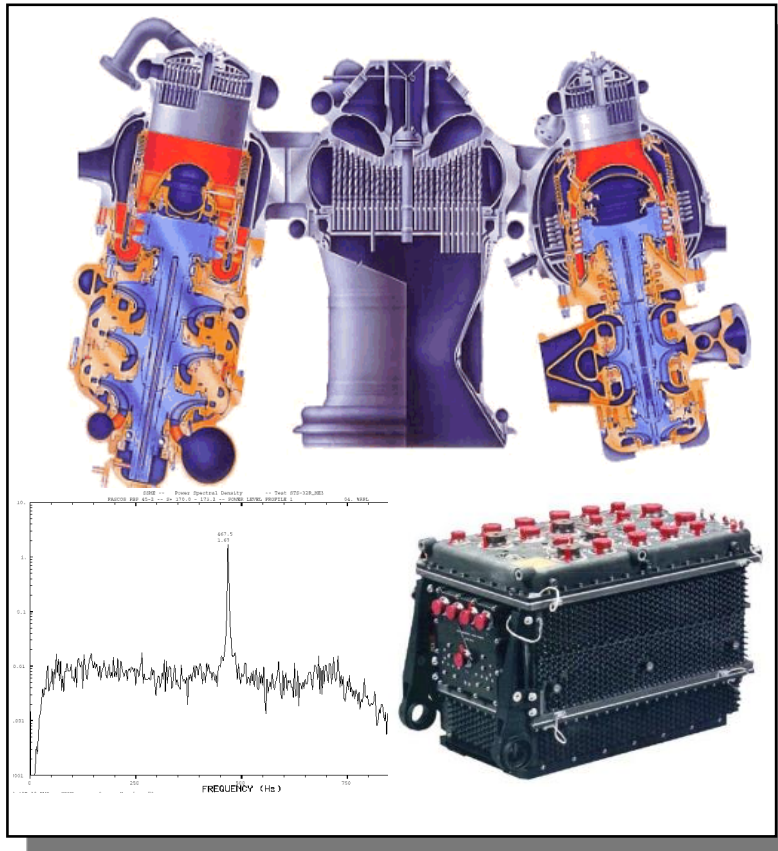

Advanced Health Management System

- Real-time spectral analysis performed to detect and measure high pressure turbopump synchronous frequencies

- Controller modified to respond to vibration data by disqualifying a sensor or shutting an engine down when necessary 


\section{SSME Ascent Risk Improvement}

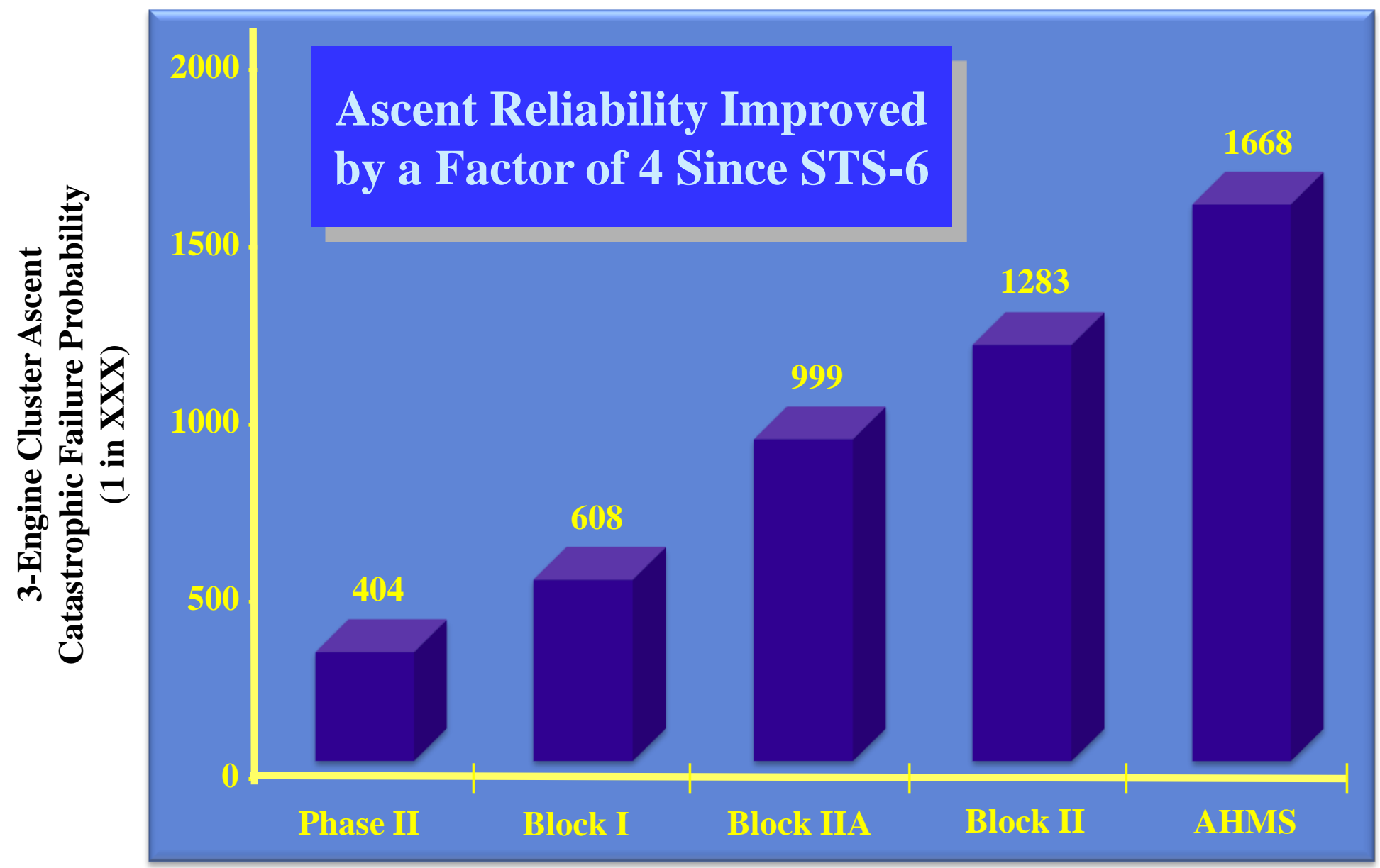

SSME Configuration 
Goal: No Delays, Scrubs, or Aborts

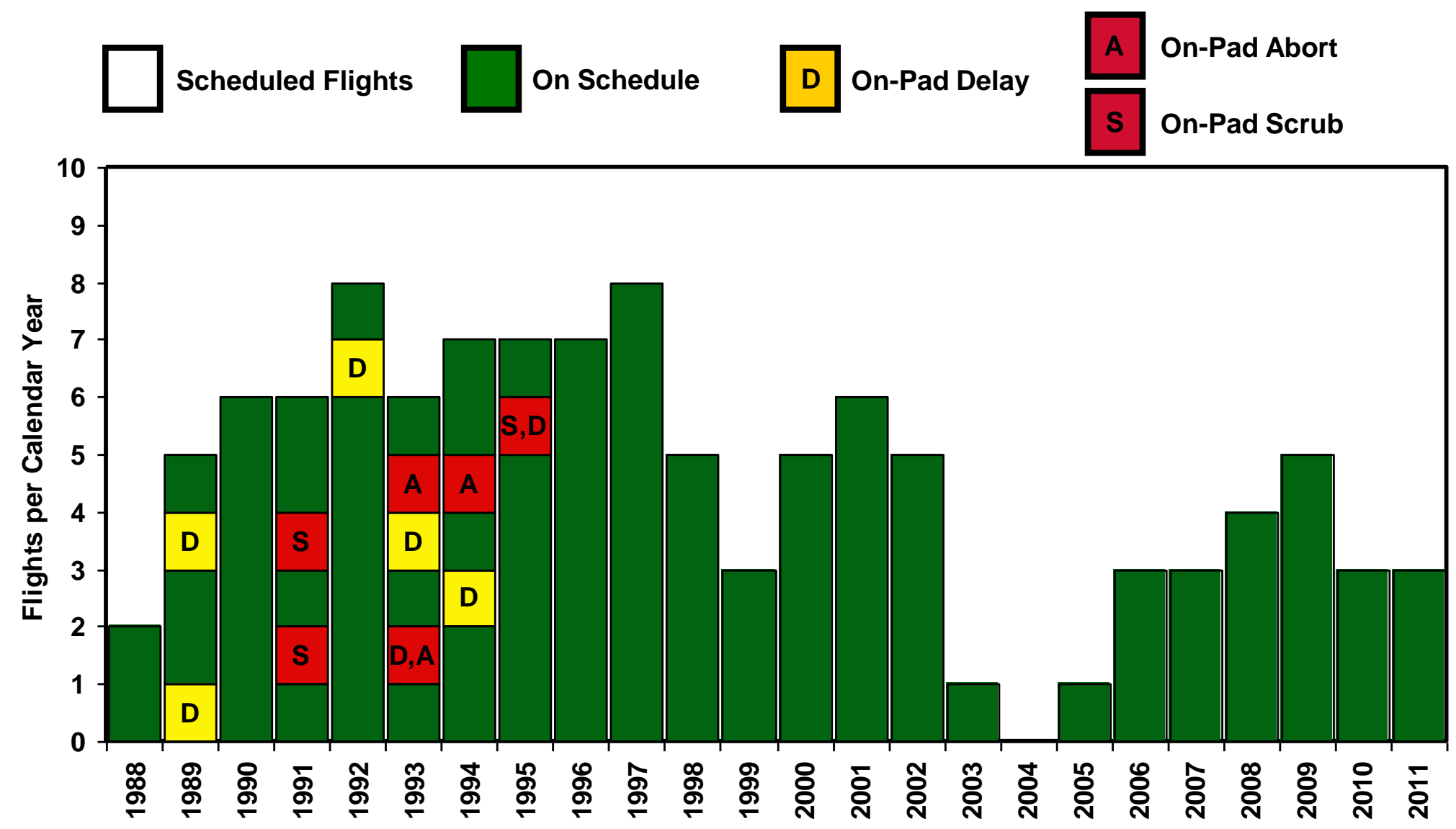

\section{Consecutive Launches Since STS-73 (October 1995) without an SSME-caused Delay, Scrub, or Abort.}




\section{SSME Maintenance Reduction}

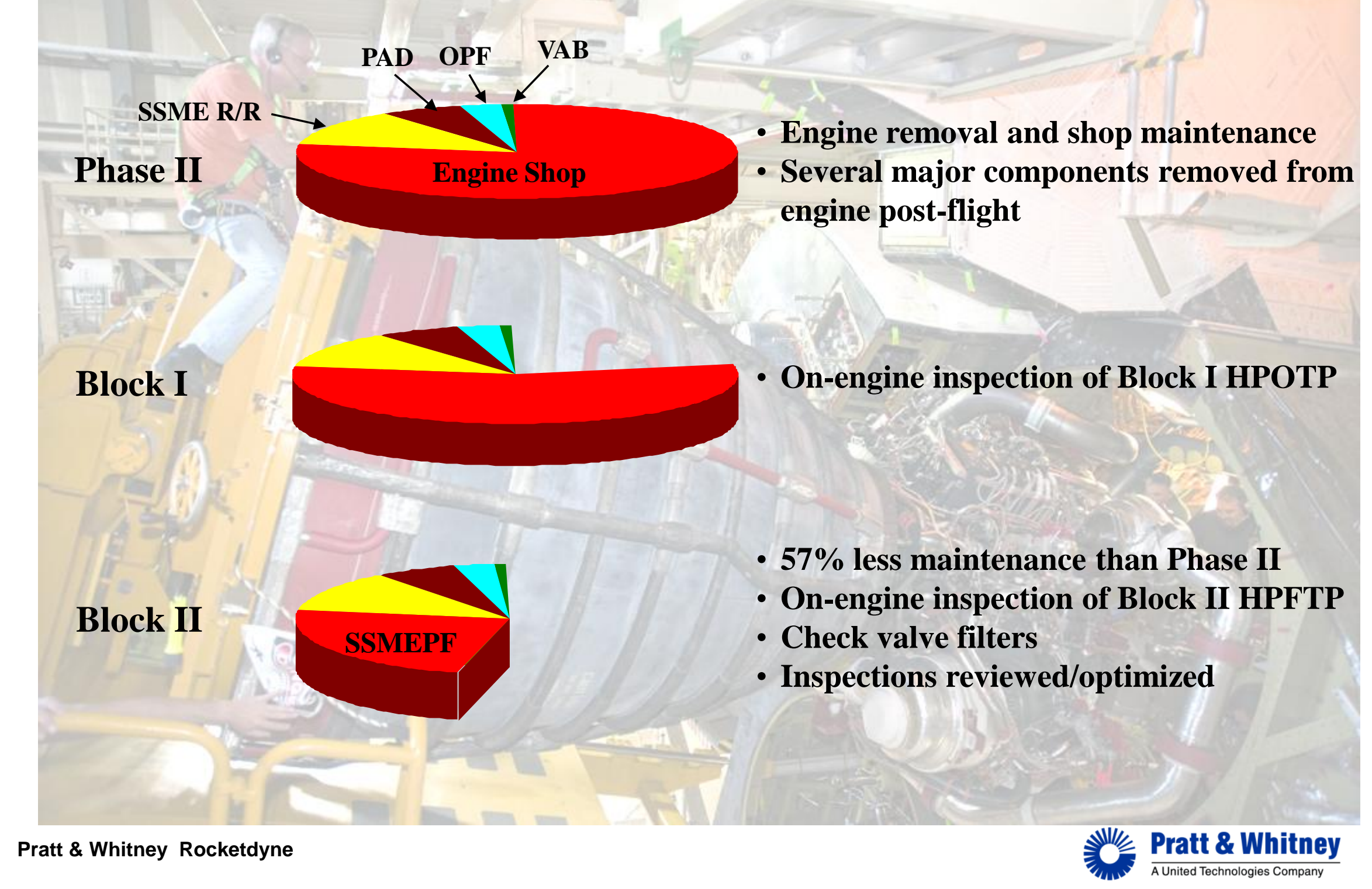




\section{SSME Ground Testing}

Key to Program Success

- Testing has been used throughout the SSME program

- In Development:

- To evaluate design integrity

- For Certification:

- To demonstrate the evolved design is ready for flight

- On the Production Design:

- To investigate and resolve anomalies

- To verify \& expand operating margins

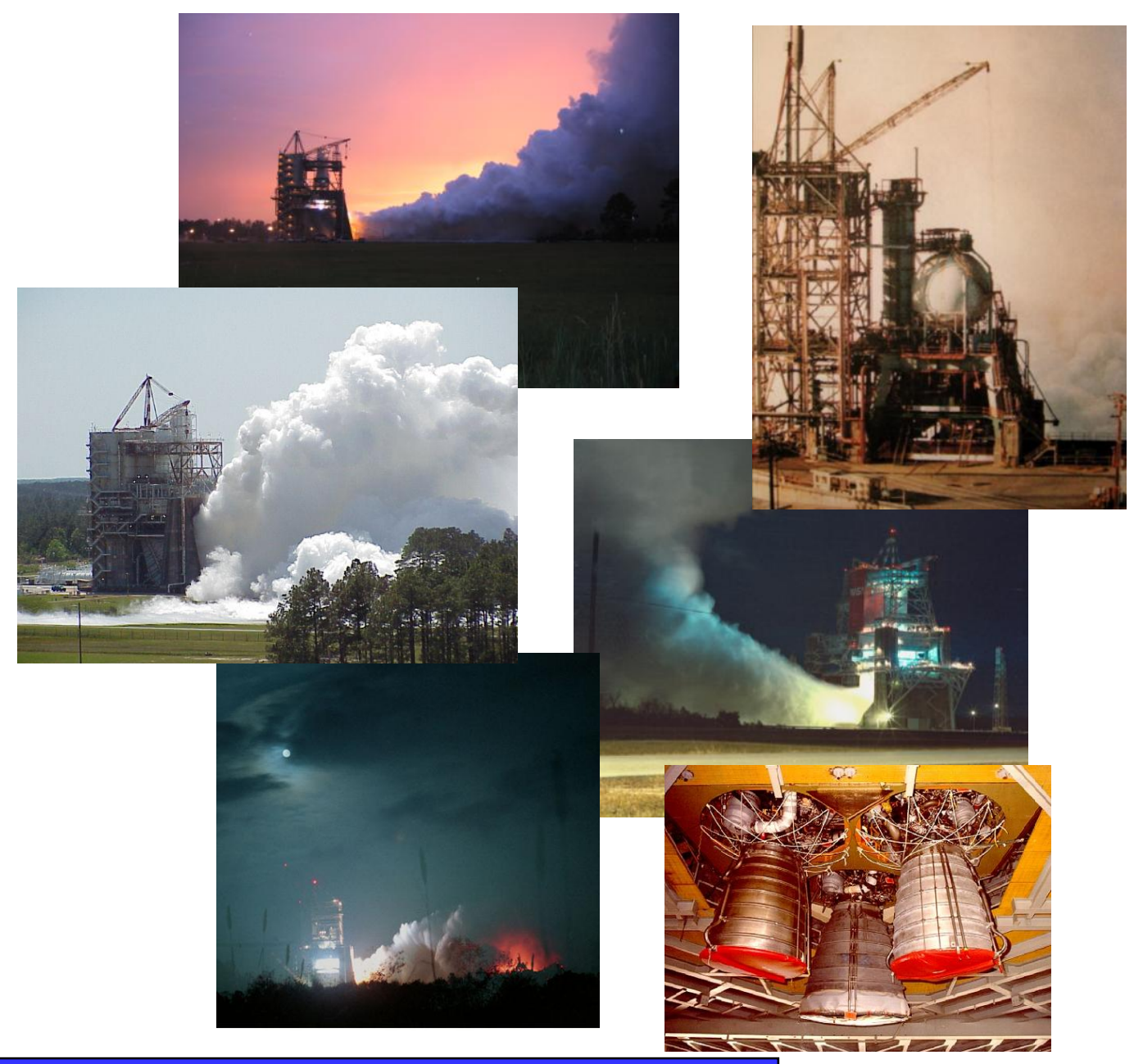

2,730 Starts / 887,717 Seconds of SSME Testing 


\begin{tabular}{|rcccl|}
\hline Mixture Ratio Control: & Open-Loop & Open-Loop & Open-Loop & Full Closed-Loop \\
\hline Thrust Control: & Open-Loop & Partial Closed-Loop & Full Closed-Loop & Full Closed-Loop \\
\hline
\end{tabular}

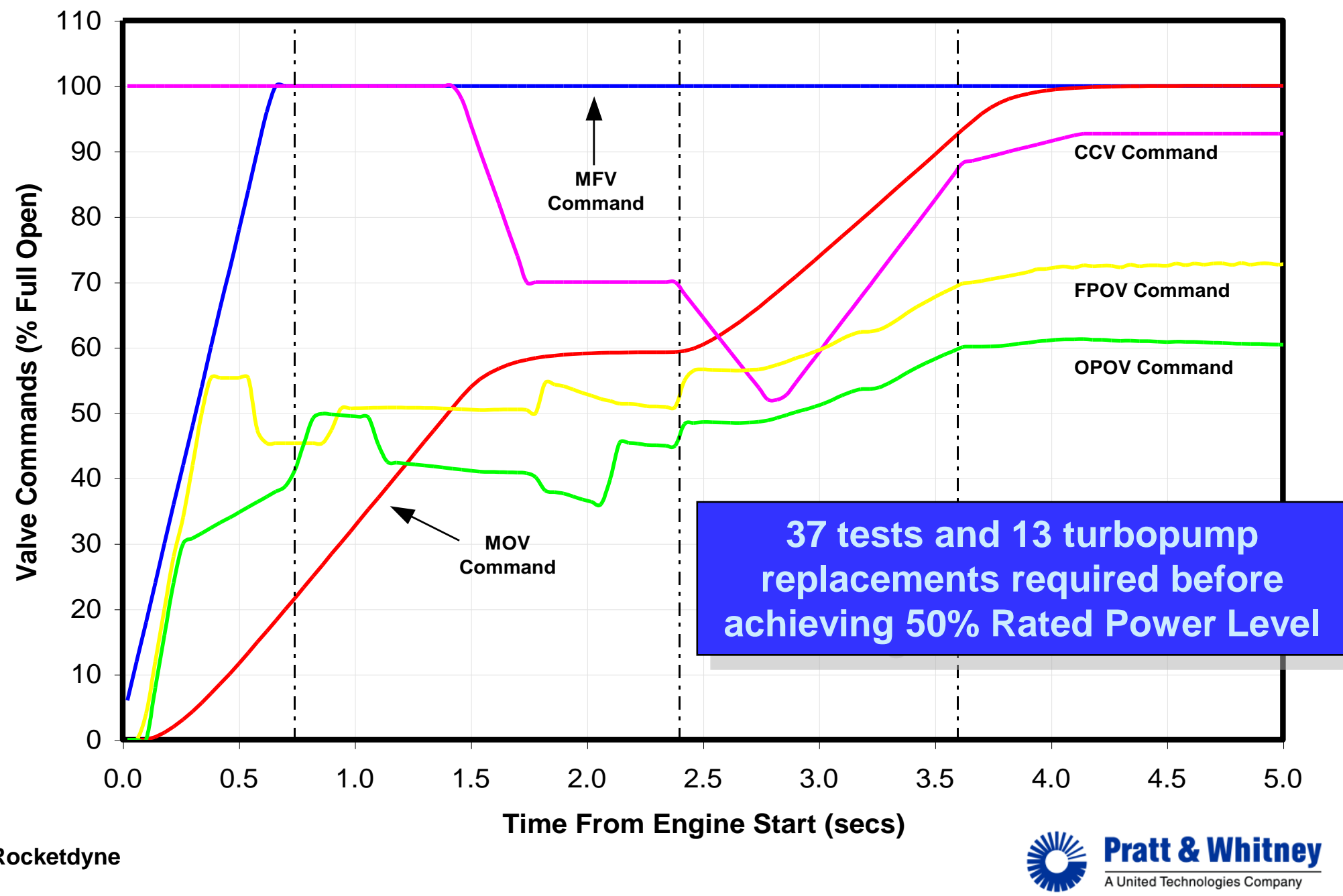




\section{Development Testing}

Data from Early in the Program

- Ninety-five tests to reach $100 \%$ RPL

- Late 1978 before first flight start sequence was finalized

- 147 design changes deemed necessary for Full Power Level (109\% RPL)

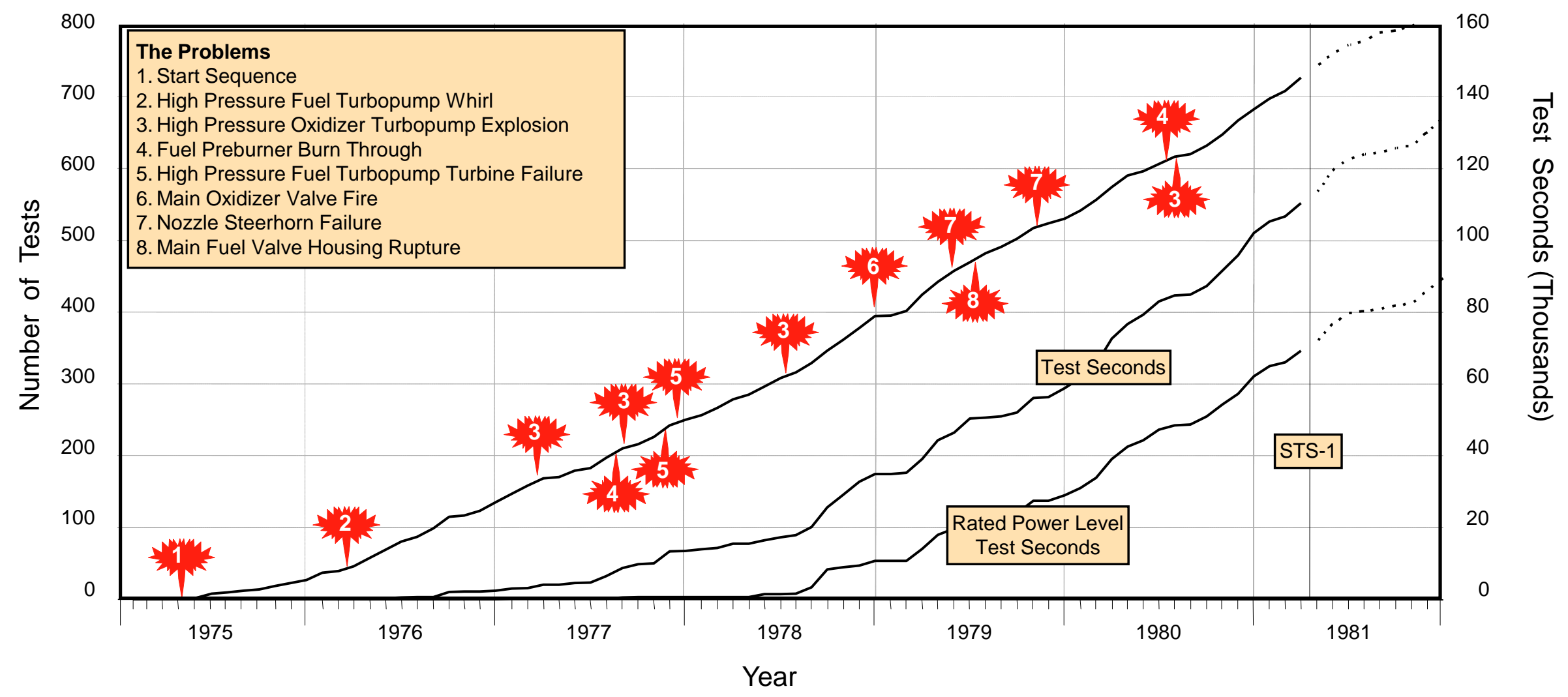




\section{Testing a Mature Design}

- Determine acceptability of flight hardware

- Investigate issues / resolve anomalies

- Issues affecting single components or engines

- Issues affecting all units of a given component

- In-Flight Anomalies

- Issues requiring tests for flight rationale

- Vehicle issues

- Verify or increase operational envelope

- Flight Rule changes or demonstration

- Off-nominal testing (operational extremes)

- Malfunction testing to demonstrate redundancy

- Overtest to demonstrate safety margins

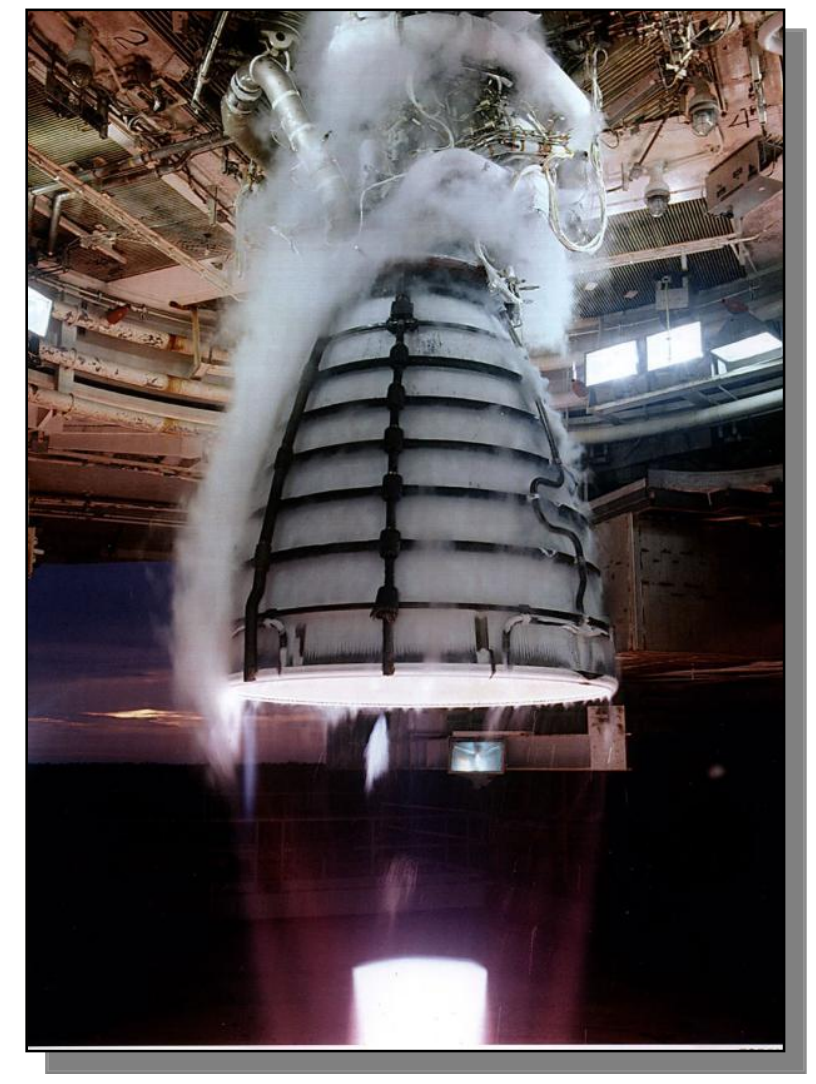

Tests have been conducted for each one of these reasons since 2000, in spite of SSME's maturity. 


\section{Conclusions About Testing}

- Testing is necessary even on a mature, well-understood, production engine

- Acceptance testing sometimes reveals issues in new hardware

- Some problems do not present themselves until late in production

- Many issues are related to the number of cycles on components

- Small numbers of assets means not all tolerance stack-ups or environments can be explored

- Process escapes can occur at any time

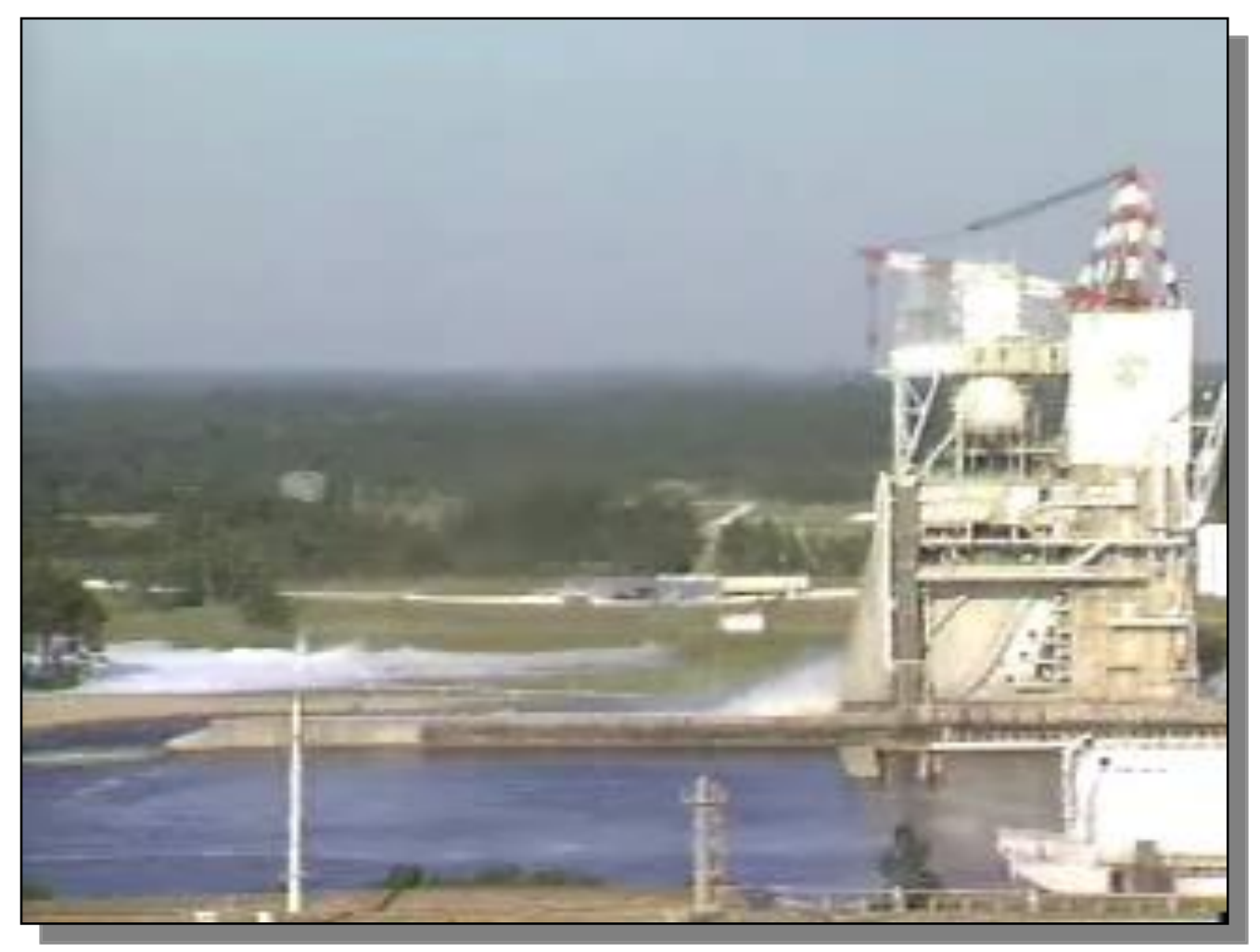

- Some design features (mating of certain components, for example) can only be demonstrated during a hotfire

- Some issues are vehicle-driven or are related to flight operations that change outside the engine program's control 


\section{Evolution of Analytical Tools, Materials Key to SSME Success}

- SSME is:

- A success because of the advances made in many engineering disciplines

- Responsible for the advancement in the state of the art in many engineering disciplines

- Advances in engineering disciplines include:

- Fluid Dynamics: Improved understanding of cavitation and increased abilities to model it

- Structural Dynamics: Increased knowledge in finite element prediction techniques, data acquisition techniques, and structural dynamics of extremely high frequency responses

- Rotordynamics: Better equipped to model and predict instability, synchronous responses, and external loading

- Materials: Continuous improvements made in material characterization and processing for reliability, performance, producibility, and reduced cost
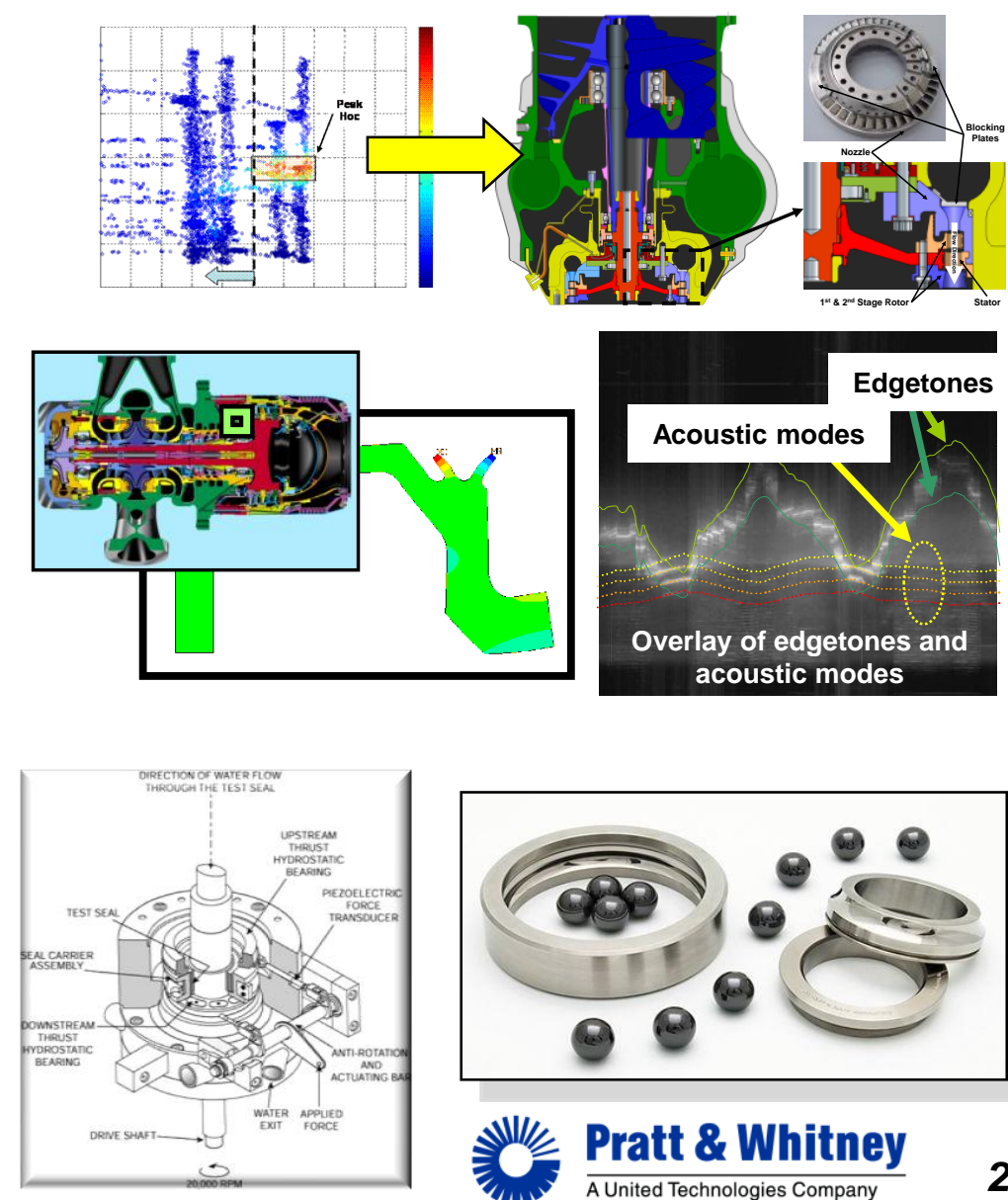

俨考, Pratt \& Whitney 


\section{Lessons from SSME's Relentless Pursuit of Improvement}

- Test outside the comfort zone

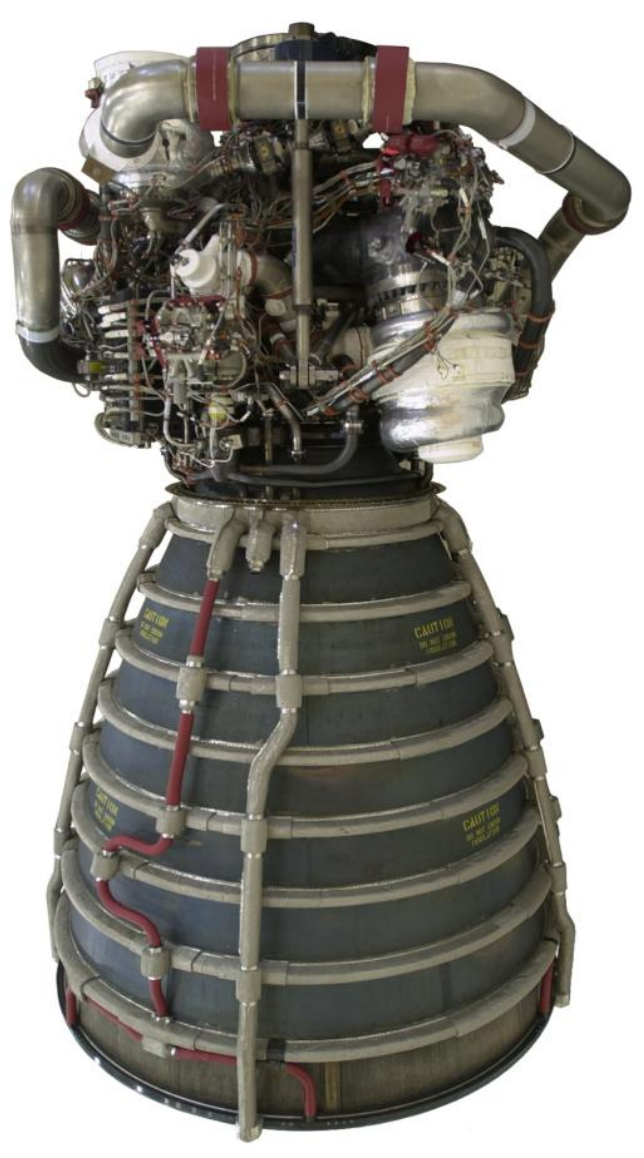

- Go beyond normal operation

- Understand margins, engine characteristics

- Use the lessons learned along the way

- Identify problems on the ground, not in flight

- Drive for understanding

- Define environments

- Be thorough in data mining

- "Listen" to the hardware

- Match models and experience

- Utilize knowledge of hands-on technicians

- Fix problems, don't manage them

- Incorporate multiple changes in blocks to reduce test costs

- Don't be afraid of unconventional ideas 